\title{
Aberrant Lck Signal via CD28 Costimulation Augments Antigen-Specific Functionality and Tumor Control by Redirected T Cells with PD-1 Blockade in Humanized Mice
}

Gulati, Pratiksha ; Rühl, Julia ; Kannan, Abhilash ; Pircher, Magdalena ; Schuberth, Petra ; Nytko, Katarzyna J ; Pruschy, Martin ; Sulser, Simon ; Haefner, Mark ; Jensen, Shawn ; Soltermann, Alex ; Jungraithmayr, Wolfgang ; Eisenring, Maya ; Winder, Thomas ; Samaras, Panagiotis ; Tabor, Annett ; Stenger, Rene ; Stupp, Roger ; Weder, Walter ; Renner, Christoph ; Münz, Christian ; Petrausch, Ulf

\begin{abstract}
Combination therapy of adoptively transferred redirected $\mathrm{T}$ cells and checkpoint inhibitors aims for higher response rates in tumors poorly responsive to immunotherapy like malignant pleural mesothelioma (MPM). Only most recently the issue of an optimally active chimeric antigen receptor $(\mathrm{CAR})$ and the combination with checkpoint inhibitors is starting to be addressed. Fibroblast activation protein (FAP)-specific CARs with different costimulatory domains, including CD28, $\Delta$-CD28 (lacking lck binding moiety), or 4-1BB were established. CAR-T cells were characterized and antitumor efficacy was tested in a humanized mouse model in combination with PD-1 blockade. Finally, the $\Delta$-CD28 CAR was tested clinically in a patient with MPM. All the three CARs demonstrated FAP-specific functionality Gene expression data indicated a distinct activity profile for the $\Delta$-CD28 CAR, including higher expression of genes involved in cell division, glycolysis, fatty acid oxidation, and oxidative phosphorylation. only T cells expressing the $\Delta$-CD28 CAR in combination with PD-1 blockade controlled tumor growth. When injected into the pleural effusion of a patient with MPM, the $\Delta$-CD28 CAR could be detected for up to 21 days and showed functionality. Overall, anti-FAP- $\Delta$-CD28/CD3 CAR T cells revealed superior functionality, better tumor control in combination with PD-1 blockade in humanized mice, and persistence up to 21 days in a patient with MPM. Therefore, further clinical investigation of this optimized CAR is warranted.
\end{abstract}

DOI: https://doi.org/10.1158/1078-0432.CCR-17-1788

Posted at the Zurich Open Repository and Archive, University of Zurich

ZORA URL: https://doi.org/10.5167/uzh-153190

Journal Article

Accepted Version

Originally published at:

Gulati, Pratiksha; Rühl, Julia; Kannan, Abhilash; Pircher, Magdalena; Schuberth, Petra; Nytko, Katarzyna J; Pruschy, Martin; Sulser, Simon; Haefner, Mark; Jensen, Shawn; Soltermann, Alex; Jungraithmayr, Wolfgang; Eisenring, Maya; Winder, Thomas; Samaras, Panagiotis; Tabor, Annett; Stenger, Rene; Stupp, Roger; Weder, Walter; Renner, Christoph; Münz, Christian; Petrausch, Ulf (2018). Aberrant Lck Signal via CD28 Costimulation Augments Antigen-Specific Functionality and Tumor Control by Redirected T Cells with PD-1 Blockade in Humanized Mice. Clinical Cancer Research, 24(16):3981-3993.

DOI: https://doi.org/10.1158/1078-0432.CCR-17-1788 


\section{Aberrant Lck signal via CD28 co-stimulation augments antigen-specific functionality and tumor control by redirected T cells with PD-1 blockade in humanized mice}

Pratiksha Gulati (1,2), Julia Rühl (2), Abhilash Kannan (3), Magdalena Pircher (1), Petra Schuberth (1), Katarzyna J Nytko (4), Martin Pruschy (4), Simon Sulser (5), Mark Haefner (6), Shawn Jensen (7), Alex Soltermann (8), Wolfgang Jungraithmayr $(9,14)$, Maya Eisenring (10), Thomas Winder (1), Panagiotis Samaras (1), Annett Tabor (11), Rene Stenger (12), Roger Stupp (1), Walter Weder (9), Christoph Renner (13), Christian Münz* (2) \& Ulf Petrausch* $(1,2)$

\section{Running title: Optimized co-stimulation through CAR with PD-1 blockade}

(1) Department of Oncology, University Hospital Zurich, Rämistrasse 100, 8091 Zürich, Switzerland

(2) Institute for Experimental Immunology, University of Zurich, Winterthurerstrasse 190, 8057 Zürich, Switzerland

(3) Institute of Molecular Life Sciences, University of Zurich, Winterthurerstrasse 190, 8057 Zürich, Switzerland

(4) Department of Radiation Oncology, University Hospital Zurich, Rämistrasse 100, 8091 Zürich, Switzerland

(5) Institute of Anesthesiology, University Hospital Zurich, Rämistrasse 100, 8091 Zürich, Switzerland

(6) Oncology Bülach, Bannhaldenstrasse 7, 8180 Bülach, Switzerland

(7) Laboratory of Molecular and Tumor Immunology, Earle A. Chiles Research Institute, Providence Cancer Center and Providence Portland Medical Center, 4805 NE Glisan St., Portland, OR 97213, USA

(8) Institute of Pathology and Molecular Pathology, University Hospital Zurich, Schmelzbergstrasse 12, 8091 Zurich, Switzerland

(9) Department of Thoracic Surgery, University Hospital Zurich, Rämistrasse 100, 8091 Zürich, Switzerland

(10) Department of Immunology, University Hospital Zurich, Rämistrasse 100, 8091 Zürich, Switzerland

(11) European Institute for Research and Development of Transplantation Strategies GmbH (EUFETS), Vollmersbachstrasse 66, 55743 Idar-Oberstein, Germany

(12) Swiss Center for Regenerative Medicine, Wyss Institute, University of Zurich, Moussonstrasse 13, 8044 Zurich, Switzerland

(13) Department of Biomedicine, University Hospital Basel, Hebelstrasse 20, 4031 Basel, Switzerland

(14) Department of Thoracic Surgery, Campus Ruppiner Kliniken, Fehrbellinerstrasse 38, 16816 Neuruppin, Medical University Brandenburg, Germany

Corresponding author: Ulf Petrausch, Institute for Experimental Immunology, University of Zurich, Winterthurerstrasse 190, 8057 Zürich, Phone: +41 4463537 01, FAX: +41 4463568 83, email: ulf.petrausch@uzh.ch

* These authors contributed equally

Conflict of Interest: The authors declare no potential conflicts of interest 
Keywords: Chimeric Antigen Receptor, Humanized mice, Malignant Pleural Mesothelioma, Fibroblast Activation Protein, Programmed Death-1 


\section{TRANSLATIONAL RELEVANCE}

One of the most pressing obstacles for immunotherapy for cancer is the development of rational based combination therapies since monotherapies only allow responses in a limited patient population. Herein we demonstrated the bench-to-bedside development of Fibroblast Activation Protein (FAP)-specific CAR redirected $T$ cells. For optimal testing of redirected $T$ cells, a humanized mouse model containing most components of the human immune system was developed. CARs with distinct co-stimulatory domains were designed and tested. We identified a particular CAR with a mutated CD28 signaling domain that provided enhanced antigen-specific proliferation, increased T-cell metabolism, activation and redirected $\mathrm{T}$ cell mediated tumor control in combination with PD-1 blockade in vivo. Additionally, we used these data to launch a first-in-human clinical trial injecting FAP-specific redirected T cells in the pleural effusion of patients with malignant pleural mesothelioma. Our preclinical and clinical data lay the groundwork for further testing of FAP-specific redirected T cells. 


\section{ABSTRACT}

Purpose: Combination therapy of adoptively transferred redirected T cells and checkpoint inhibitors aims for higher response rates in tumors poorly responsive to immunotherapy like malignant pleural mesothelioma (MPM). Only most recently the issue of an optimally active chimeric antigen receptor (CAR) and the combination with checkpoint inhibitors is starting to be addressed.

Experimental design: Fibroblast Activation Protein (FAP)-specific CARs with different co-stimulatory domains including CD28, $\triangle-C D 28$ (lacking Ick binding moiety) or 4-1BB were established. CAR-T cells were characterized in vitro and anti-tumor efficacy was tested in vivo in a humanized mouse model in combination with PD-1 blockade. Finally, the $\Delta-C D 28$ CAR was tested clinically in a MPM patient.

Results: All the three CARs demonstrated FAP-specific functionality in vitro. Gene expression data indicated a distinct activity profile for the $\Delta$-CD28 CAR including higher expression of genes involved in cell division, glycolysis, fatty acid oxidation and oxidative phosphorylation. In vivo, only T cells expressing the $\Delta$ CD28 CAR in combination with PD-1 blockade controlled tumor growth. When injected into the pleural effusion of a MPM patient, the $\triangle$-CD28 CAR could be detected for up to 21 days and showed functionality.

Conclusions: Overall, anti-FAP- $\Delta-C D 28 / C D 3 \zeta$ CAR $T$ cells revealed superior in vitro functionality, better tumor control in combination with PD-1 blockade in humanized mice, and persistence up to 21 days in a MPM patient. Therefore, further clinical investigation of this optimized CAR is warranted. 


\section{INTRODUCTION}

Chimeric antigen receptor (CARs) are composed of an antibody derived, target antigen specific single-chain variable fragment (scFv) which is linked to T-cell costimulatory domains such as CD28, 4-1BB, ICOS, CD27 or OX40 in addition to the T-cell signaling domain $\mathrm{CD} 3 \zeta$ (1). CARs can be designed to recognize tumor associated antigens (TAAs) and thereby can be utilized to redirect $T$ cells against cancer cells.

Until now, most remarkable clinical responses have been observed using anti-CD19-CARs in hematological malignancies (2). Based on these promising results, redirected $T$ cell therapy needs further evaluation, to allow for clinical benefit in other malignancies, especially solid tumors.

Pre-clinical evaluation of redirected $T$ cells often employs immune compromised mouse models. These models provide limited understanding of the interplay between human tumors and redirected T cells, without depicting interactions with other immune system components. Unlike in a human host, the transferred T cells cannot benefit from human cytokines like IL-7 and IL-15 (3). Furthermore, in immune compromised mice adoptive transfer of $\mathrm{T}$ cells educated outside the mouse host can result in graft-versus-host-disease (GvHD) (3). Humanized mouse models overcome some of these limitations and have demonstrated to be a powerful model system at least for the study of human viruses (4). Using human hematopoietic progenitor cells (HPCs), immune compromised mice develop most human lymphocyte and myeloid lineages (5). Attributed to the partly developed human immune environment, humanized mice can provide a robust host, for blocking or boosting anti-cancer immune reactions mediated by adoptively transferred redirected $\mathrm{T}$ cells.

Malignant pleural mesothelioma (MPM) is a disease which cannot be cured even at early stages (6). Recently, encouraging data using PD-1 blocking antibodies indicated that the immune system can attack MPM and result in clinical responses $(7,8)$. However, only a minority of patients responded to PD-1 blockade. One possible explanation could be the absence of a T-cell repertoire that can generate a therapeutic immune response. A potential approach to overcome this limitation is transfer of redirected $T$ cells recognizing antigens expressed in MPM. Fibroblast Activation Protein (FAP) is expressed in MPM and is therefore a potential target antigen (9). We constructed anti-FAP (scFv F19) 
CAR constructs with different co-stimulatory moieties, CD28, $\triangle-C D 28$ and 4-1BB and tested them in vitro and in a humanized mouse model. The $\triangle$-CD28 CAR carries a deletion in the Ick binding domain which was initially shown to augment anti-tumor responses due to aberrant IL-2 production which was no longer available to sustain persistence of Tregs, infiltrating tumors (10).

Our data indicate that the $\triangle-C D 28$ CAR mediates superior in vitro functionality, showed enhanced metabolism, activation after cognate antigen encounter, and mediated better tumor control in combination with PD-1 blockade in humanized mice. Based on these findings, the $\Delta$-CD28 CAR was further used for a first in-man adoptive transfer of FAP-specific redirected T cells in MPM patient. This study provides the rationale for further exploring FAPspecific $\Delta$-CD28 CAR redirected T cells in patients with MPM and other malignant tumours expressing FAP. 


\section{METHODS}

\section{Cell lines}

293T cells were purchased from ATCC (Manassas, VA, USA). HT1080FAP and HT1080PA cell lines were generated by stably transfecting HT1080 cells with human FAP or mock plasmid, respectively, in addition to the luciferase plasmid, as described previously (11). All cell lines were routinely tested and confirmed negative for mycoplasma contamination. For details about culturing conditions, refer to supplemental notes.

\section{T cell activation with anti-CD3/CD28}

$\mathrm{CD}^{+} \mathrm{T}$ cells isolated from healthy leucocyte concentrate donors were incubated with CD3/28 beads at 1:5 bead:cell ratio or anti-CD3 and anti-CD28 antibodies (1ug/ml) either supplemented in T cell medium (TCM; RPMI + 2mM L-glutamine $+10 \% \mathrm{FBS}+50 \mathrm{U} / \mathrm{ml}$ penicillin $+50 \mu \mathrm{g} / \mathrm{ml}$ streptomycin and $1 \mathrm{X}$ NEAA (Nonessential amino acids solution)) or coated on 24 well plates (Corning). After 48 hours, the CD3/28 stimulus was removed and cells were incubated in TCM supplemented with $200 \mathrm{IU} / \mathrm{ml} \mathrm{IL-2} \mathrm{(Peprotech,} \mathrm{NJ,} \mathrm{USA),} \mathrm{and} \mathrm{10ng/ml} \mathrm{of} \mathrm{both} \mathrm{IL-}$ 7 and IL-15 (Miltenyi Biotech). Alternatively, cells were labelled with CFSE and CFSE dilution assays were performed as described before (12). Phenotypic markers were analyzed by flow cytometry at several time points after removal of the CD3/28 stimulus.

\section{Generation of CAR constructs and retroviral transduction of T cells}

The single chain variable fragment (scFv) of the FAP-specific CAR (F19) (11) and the NY-ESO-1 specific CAR (T1), which serves as control in this study (recognizing the HLA-A*02:01/NY-ESO- $1_{157-165}$ peptide complex) (13) flanked by NCOI and BamHI restriction sites, was cloned into the pBullet vector (14), containing a human $\Delta-\mathrm{CH} 2 / \mathrm{CH} 3$ domain of the co-stimulatory domains of either $\mathrm{CD} 28, \Delta$ $\mathrm{CD} 28$ or $4-1 \mathrm{BB}$, and the $\mathrm{CD} 3 \zeta$ domain (kindly provided by Dr. Hinrich Abken, University of Cologne, Germany). The human $\Delta-\mathrm{CH} 2 / \mathrm{CH} 3$ domain contains a modification which reduces binding of the respective CARs to $\mathrm{FcyR}^{+}$cells (15) and thereby minimizes off-target activation. The $\Delta-C D 28$ is a modification of the CD28 co-stimulatory domain (generated by site directed mutagenesis), which is devoid of the Ick kinase binding site (10). The resulting CAR constructs were 
termed: FAP-specific: F19-CD28/CD3 $\zeta$, F19- $\Delta-C D 28 / C D 3 \zeta$ or $\mathrm{F} 19-4-1 B B / C D 3 \zeta$

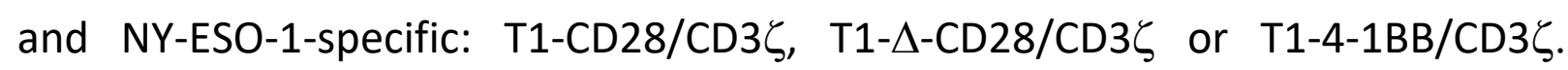
Retroviral transduction of human peripheral $\mathrm{CD}^{+} \mathrm{T}$ cells was performed as previously described (13). Cells were cultured in TCM with $200 \mathrm{IU} / \mathrm{ml} \mathrm{IL-2}$ (Peprotech, NJ, USA), 10ng/ml of both IL-7 and IL-15 (Miltenyi Biotech). After transduction, CAR-T cells were rested for 4 days in culture before use in an assay.

\section{Flow cytometry}

Staining for cell surface markers was carried out by incubating with antibodies for $30 \mathrm{~min}$ on ice. For intracellular stainings, the fixation and permeabilization kit from eBioscience was used, as per manufacturer's instructions. All samples were stained with viability dye to exclude dead cells. The samples were measured on a FACSCanto II or LSR Fortessa cytometer (BD Biosciences). Data was analyzed using FlowJo software (Treestar). For details about staining antibodies, refer to supplemental notes.

\section{In vitro functional assays}

Cytotoxicity assays were performed as previously described (16) and as outlined in the supplemental notes.

T-cell proliferation was determined in vitro using bromodeoxyuridine (BrdU) APC flow kit (BD Biosciences). Briefly, CAR-T cells were seeded on FAP ( $R$ and D Systems) coated $(2 \mathrm{ug} / \mathrm{ml})$ cell culture plates (Thermo Fischer scientific) and incubated at $37^{\circ} \mathrm{C}$ and $5 \% \mathrm{CO}_{2}$ for 72 hours followed by addition of $\mathrm{BrdU}$ $(10 \mu \mathrm{M})$ and incubation for another 72 hours. The cells were harvested and staining for BrdU was performed as per manufacturer's instructions followed by analysis in a flow cytometer.

To analyse cytokine release, supernatants of co-cultivated effector and target cells were collected after 12 hours of incubation. IFN- $\gamma$ and IL-2 levels were detected using BD OptEIA human IFN- $\gamma$ and human IL-2 ELISA kits, respectively, according to the manufacturer's instruction (BD Biosciences). Cytokines IL-2, IL-6, IL-10, IFN- $\gamma$ and TNF- $\alpha$ from human samples were measured using a multiplexed particle-based flow cytometric cytokine assay employing cytokine Luminex kits (R\&D Systems, Oxon, UK) (17). 


\section{RNA sequencing}

$\mathrm{CD}^{+} \mathrm{T}$ cells isolated from three buffy donors $(\mathrm{N}=3)$ using $\mathrm{CD} 8$ microbeads (Miltenyi Biotech) were transduced to express $\mathrm{F} 19-\mathrm{CD} 28 / \mathrm{CD} 3 \zeta, \mathrm{F} 19-\Delta-$

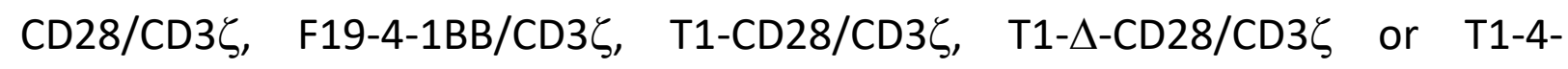
$1 \mathrm{BB} / \mathrm{CD} 3 \zeta$ CARs. After transduction, cells were stimulated with recombinant human FAP for 6 days and $\mathrm{CAR}^{+} \mathrm{T}$ cells were flow sorted on an Aria III cell sorter (BD Biosciences). Average $1 \times 10^{6}$ sorted $\mathrm{CAR}^{+} \mathrm{CD} 8^{+}$cells with purity $>95 \%$ were used for RNA extraction using ZymoQuick RNA MicroPrep kit (Lucerna-Chem, Luzern, Switzerland) as per manufacturer's instructions. RNA sequencing was performed at the Functional Genomics Center Zurich (FGCZ) and data analyzed using Bioconductor EdgeR software package. For detailed description of RNA sequencing methods and analysis, refer to supplemental notes. To validate sequencing data, redirected $T$ cells produced from healthy donors were stimulated with recombinant human FAP for 6 days and expression of phenotypic markers was analyzed by flow cytometry.

\section{Humanized mice and adoptive T cell transfer}

Human fetal livers (HFL) were obtained from Advanced Bioscience Resources (Alameda, CA, USA). Leukapheresis products were left over from patients which initially were allocated autologous $\mathrm{CD}^{+} 4^{+}$transplantation but did not need further treatment (Department of Oncology, University Hospital Zurich, Switzerland). Isolation of $\mathrm{CD}_{3} 4^{+}$cells was performed as per the established protocol (18) and using CD34 microbeads (Miltenyi Biotech) as per manufacturer's instructions. Purity of CD34 fraction was assessed by FACS and the cells were cryopreserved (RPMI + 7.5\% DMSO + 20\% FBS). NOD-scid IL2R $\gamma^{\text {null }}$ (NSG) mice were obtained from the Jackson Laboratory, and bred and raised under specific pathogen-free conditions at the Biologisches Zentrallabor (BZL), University Hospital Zurich, Switzerland. For humanization, newborn NSG mice received $2 \times 10^{5}$ or $2 \times 10^{6} \mathrm{CD} 34^{+}$obtained from $\mathrm{HFL}$ or leukapheresis, respectively, as per protocol described previously (19) and in Figure S4, A.

To test survival of redirected T cells, FAP-specific $0.2 \times 10^{6} \mathrm{CAR}^{+} \mathrm{CD}^{+}$cells produced from harvested splenocytes of donor huNSG mice, were intravenously injected into recipient huNSG mice (reconstituted with same CD34 ${ }^{+}$HPCs as donor huNSG mice). Persistence of redirected T cells in the blood or abdominal organs (at the time of sacrifice) was measured by qPCR. To test the anti-tumor 
efficacy of redirected T cells, luciferase expressing HT1080FAP tumor cells ( $0.1 \mathrm{X}$ $10^{6}$ cells per mouse) were injected intra-peritoneally (i.p.) in huNSG. Tumor development was measured by in vivo bioluminescence imaging using IVIS ${ }^{\circledR 200}$ Caliper (Caliper Life Sciences, MA, USA) as described previously (11) and based on the tumor burden at day 1 , mice were equally distributed in groups. This was followed by adoptive transfer of redirected T cells i.p. at effector/target (E:T) ratio of 4:1 to 8:1. In addition to this, mice were injected intra-peritoneally with PD-1 blocking antibody ( $200 \mu \mathrm{g}$ per mouse), every fourth day. Tumor volume was measured by bioluminescence as Total Flux (photons/second) and quantified for each animal using software Living Image 3.2 (Caliper Life Sciences) as described previously (11). Mice were regularly monitored and euthanized when the change in body weight exceeded $15 \%$ or when they displayed persistent discomfort or deviations from normal behaviour.

\section{Quantitative PCR to detect redirected T cells}

Cellular DNA was extracted using DNeasy blood and tissue kit (Qiagen, Germany). CAR DNA was quantified by real-time PCR using primers Fwd 5'GAAGATGAGCTGCAAGACCA-3'; Rev 5'-GCCCTTGAACTTCTGGTTGT-3'; Probe 5'(6FAM)-GTACACCATCCACTGGGTCC-(TAMRA)-3' and Taqman Universal PCR Master Mix (Applied Biosystems, CA, USA). The samples were measured in a CFX-384 Touch Real-Time PCR Detection System (Bio-Rad, CA, USA). All samples were tested at least in triplicates.

\section{Study Approval and Clinical Trial}

All animal experiments were performed in accordance with the Swiss federal and cantonal laws on animal protection (KEK-ZH-Nr. 2011-0498, KVET 10/2013 and 41/2016). The clinical trial was approved by the cantonal ethics committee of Zürich, Switzerland (ethical committee KEK-ZH-Nr. 2012-0106, registered under NCT01722149). Informed consent was obtained from the trial subject and the trial was conducted in accordance to the principles enunciated in the current version of the Declaration of Helsinki (DoH), the Essentials of Good Epidemiological Practice issued by Public Health Schweiz (EGEP), the Swiss Law and Swiss regulatory authority's requirements as applicable. The clinical trial for the complete recruitment is still ongoing. No primary endpoints are reported here. For details on clinical trial design, refer to supplemental notes. 


\section{RESULTS}

\section{Stimulation with anti-CD3/CD28 coated beads lead to enhanced activation and reduced expression of senescence marker.}

The ability to expand tumor specific $T$ cells without impairing their functional capacity is crucial for the success of adoptive immunotherapies in cancer. We investigated the consequences of anti-CD3 and anti-CD28 (CD3/28) stimulation provided by beads or antibodies (either in suspension or plate coated), on the proliferation, phenotype of $T$ cells and their ability to get transduced to express CARs. T cells stimulated with CD3/28 beads or antibodies were monitored for several phenotypic markers at different time points (day 0 , $3,5,7$ and 10) after removal of $C D 3 / 28$ stimulus (Figure $1 A$ ). CD3/28 bead stimulation led to increased $T$ cell activation over $\mathrm{CD} 3 / 28$ antibodies, as indicated by significantly higher frequencies of $\mathrm{CD}^{+} 5^{+}$cells (20). Additionally, frequency of $\mathrm{CD} 9^{+}$(early marker of $\mathrm{T}$ cell activation), $\mathrm{PD}-1^{+}$and $\mathrm{Ki} 67^{\text {bright }}$ (proliferation marker) cells, was significantly higher in $\mathrm{CD} 3 / 28$ beads stimulated cells, immediately after removal of stimulus (day 0 ). In contrast, frequency of $\mathrm{CD} 7^{+}$cells, indicating replicative senescence (21), was significantly less in CD3/28 beads activated cells at day 10 after stimulation (Figure $1 A$ ). Using CFSE, we observed a trend of increased proliferation in T cells stimulated with CD3/28 beads, which was significantly different from cells that receive no activation stimulus (Figure 1B). Besides this, there was no difference in the ability of CD3/28 antibody or $\mathrm{CD} 3 / 28$ beads activated $T$ cells to get transduced and express CARs (Figure 1C). CAR-T cells activated with $C D 3 / 28$ beads produced significantly higher levels of IL-2 upon antigen-specific stimulation. Nonetheless, antigen-specific IFN- $\gamma$ secretion remained unaffected (Figure 1D and 1E). These findings indicate reduced senescence attributed to lesser frequency of $\operatorname{CD} 57^{+}$ cells and higher proliferation and expansion potential due to increased frequencies of Ki $67^{\text {bright }}$ cells and further, higher levels of IL- 2 production by CAR$T$ cells generated after activation with $C D 3 / 28$ beads. Thus, we used CD3/28 beads to produce redirected $T$ cells for further experiments.

Deletion of Lck binding domain in CD28 co-stimulatory moiety provides an activated cell-like gene expression profile in redirected $T$ cells upon antigen encounter. 
FAP specific (F19) and control (T1) redirected T cells with the different costimulations $\mathrm{CD} 28 / \mathrm{CD} 3 \zeta, \Delta-\mathrm{CD} 28 / \mathrm{CD} 3 \zeta$ \& 4-1BB/CD3 $\zeta$ (Figure $\mathrm{S} 1, \mathrm{~A}$ ) were stimulated with FAP. Firstly, we were interested to identify and compare (fold change (Log2FC)) differentially regulated genes in antigen specific over control

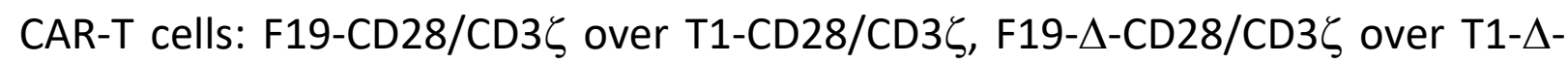
$\mathrm{CD} 28 / \mathrm{CD} 3 \zeta$ and $\mathrm{F} 19-4-1 \mathrm{BB} / \mathrm{CD} 3 \zeta$ over $\mathrm{T} 1-4-1 \mathrm{BB} / \mathrm{CD} 3 \zeta$ (Figure $\mathrm{S} 2, \mathrm{~A}$ ) to identify differences in co-stimulation, which could endow CAR-T cells with improved tumor targeting properties, ideal survival and efficacy. $\Delta-C D 28 / C D 3 \zeta$ costimulation resulted in higher expression of cell cycle genes; indicating enhanced proliferation in an antigen-specific manner (Figure 2A (i), genes listed in table S1). T cells undergo dynamic metabolic changes during an immune response, which can decide their differentiation and fate (22). We observed that the $\Delta$ CD28/CD3 $\zeta$ co-stimulation resulted in relatively increased expression of genes that control cell metabolism such as glycolysis, fatty acid oxidation and oxidative phosphorylation (Figure S2, C). Consistent with this observation, the plasma membrane transporters which play a predominant role in cell metabolism (22) were most distinctly regulated in response to $\Delta-\operatorname{CD} 28 / C D 3 \zeta$ co-stimulation (Figure S2, B). We additionally considered key signature markers that distinguish effector T-cells from memory T-cells. The expression of genes such as IL-7R, IL15, AMPK (PRKAA1, PRKAB2 and PRKAG2), TSC1 (negative regulator of mTOR) and SIRT1, which provide a more memory like T-cell phenotype were increasingly reduced in $\Delta-\mathrm{CD} 28 / \mathrm{CD} 3 \zeta$ co-stimulation (Figure $2 \mathrm{~A}$ (ii)). Activation and proliferation of effector $T$ cells is often accompanied by increased levels of inhibitory receptors (20). We found that although $\Delta-C D 28 / C D 3 \zeta$ co-stimulation resulted in enhanced expression of these receptors, e.g. CTLA4, BTLA, ENTPD1 (CD39) and HAVCR2 (Tim-3), it also demonstrated reduced expression of preapoptotic genes and increased expression of anti-apoptotic genes (Figure 2A (iii)). Besides, we observed enhanced upregulation of positive and downregulation of negative regulators of autophagy in redirected T cells with $\Delta$ $\mathrm{CD} 28 / \mathrm{CD} 3 \zeta$ co-stimulation (Figure S2, D). Albeit, the exact relation between autophagy and apoptosis is controversial, research evidence indicates that autophagy can promote T-cell survival by negatively impacting cell death and plays a role in memory formation $(23,24)$. Overall, our sequencing data indicated a distinct genetic signature consistent with, highly proliferating, actively metabolizing and a terminally differentiated cell like biology of redirected T cells 
in response to $\triangle-C D 28 / C D 3 \zeta$ co-stimulation. To further reveal the specific transcriptional response to $\triangle-C D 28 / C D 3 \zeta$ CAR activation, we additionally compared the transcriptome of FAP specific $\Delta-C D 28 / C D 3 \zeta$ CAR expressing T cells after antigen stimulation with the other two FAP specific CARs (F19- $\Delta$ -

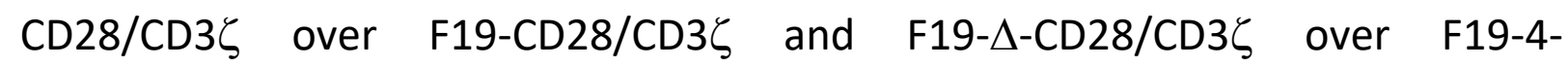
$1 B B / C D 3 \zeta)$. Log2FC of genes identified before and related to cell cycle, cytokines, effector or memory phenotype in T-cells was analyzed (Figure 2B). Primarily cell cycle genes were higher expressed in $\triangle$-CD28/CD3 $\zeta$ CAR expressing $T$ cells after antigen encounter in comparison to the 4-1BB/CD3 $\zeta C A R$, while these were already constitutively expressed by CD28/CD3 $\zeta$ CAR carrying $T$ cells without antigen encounter. Further, to validate our findings at the protein level, we analyzed the expression of Ki67 (proliferation marker), CD25 (activation marker), PD-1 and Tim-3 (activation/exhaustion markers) on FAP specific (F19$\mathrm{CD} 28 / \mathrm{CD} 3 \zeta$, F19- $\Delta-\mathrm{CD} 28 / \mathrm{CD} 3 \zeta$ and $\mathrm{F} 19-4-1 \mathrm{BB} / \mathrm{CD} 3 \zeta$ ) and control (T1$\mathrm{CD} 28 / \mathrm{CD} 3 \zeta, \mathrm{T} 1-\Delta-\mathrm{CD} 28 / \mathrm{CD} 3 \zeta$ and $\mathrm{T} 1-4-1 \mathrm{BB} / \mathrm{CD} 3 \zeta) \mathrm{CAR}-\mathrm{T}$ cells after 6 days of stimulation with FAP. We observed that proliferation and activation was increased in an antigen specific manner in response to $\Delta-C D 28 / C D 3 \zeta$ than CD28/CD3 $\zeta$ or $4-1 B B / C D 3 \zeta$ co-stimulations, as indicated by higher frequencies of $\mathrm{Ki}^{\text {bright }}$ and $\mathrm{CD} 25^{+}$cells in $\mathrm{F} 19-\Delta-\mathrm{CD} 28 / \mathrm{CD} 3 \zeta$ over $\mathrm{T} 1-\Delta-\mathrm{CD} 28 / \mathrm{CD} 3 \zeta \mathrm{CAR}-\mathrm{T}$ cells of $\mathrm{CD}^{+}$or $\mathrm{CD}^{+} \mathrm{T}$ cell lineages (Figure $2 \mathrm{C}$ ). In addition to this, the frequency of PD- $1^{+}$cells was antigen-specifically enhanced only upon $\triangle$-CD28/CD3 $\zeta$ costimulation, while Tim-3 expression was consistently augmented in FAP-specific $\mathrm{CD} 28 / \mathrm{CD} 3 \zeta, \triangle-\mathrm{CD} 28 / \mathrm{CD} 3 \zeta$ and 4-1BB/CD3 $\zeta$ CARs over their respective controls. There were no remarkable differences observed between FAP-specific CD28/CD3 $\zeta$ or $\triangle-C D 28 / C D 3 \zeta$ CAR-T cells, besides both of them being significantly distinct from $4-1 B B / C D 3 \zeta$ CAR in terms of expression of activation/exhaustion markers, PD-1 and Tim-3 (Figure 2C). There were no differences in the expression of apoptotic markers, Bcl-2 (anti-apoptotic) and Bax (pro-apoptotic) at the protein level (Figure S2, E). CAR-T cells demonstrated in general, a more central memory and effector memory like phenotype compared to non-transduced $\mathrm{T}$ cells, irrespective of co-stimulatory signal conferred upon antigen binding (Figure S1, B).

Thus, we confirm that antigen-specific $\Delta$-CD28 co-stimulation provided an exceedingly activated cell like profile to redirected T cells, as demonstrated by 
enhanced frequencies of $\mathrm{CD} 25^{+}, \mathrm{Ki} 67^{\text {bright }}$ and $\mathrm{PD}-\mathrm{1}^{+}$redirected cells along with increased Tim-3 expression. This phenotype was already displayed in part without antigen stimulation by $\mathrm{CD} 28 / \mathrm{CD} 3 \zeta$ CAR expressing $T$ cells and never to the same extent achieved by $4-1 B B / C D 3 \zeta$ CAR carrying $T$ cells even after antigen stimulation.

\section{Aberrant Lck signaling through the CD28 CAR increases the antigen-specific proliferation of redirected T cells.}

Next, we investigated the impact of different co-stimulations on proliferation and efficacy of redirected $T$ cells in vitro. Over multiple experiments with several donors $(n=8)$ we observed that $C D 28 / C D 3 \zeta$ CAR-T cells proliferated un-specifically. In contrast, the $\Delta-C D 28 / C D 3 \zeta$ and $4-1 B B / C D 3 \zeta C A R-$ $T$ cells proliferated equally well in a highly antigen-specific manner (Figure $3 A$ ). Additionally, we observed that the $\mathrm{CD} 8^{+}$CAR-T cells demonstrated significantly higher non-specific proliferation compared to $\mathrm{CD} 4^{+}$CAR-T cells (Figure S1, C). Notably, all three co-stimulatory CAR constructs demonstrated antigen-specific anti-tumor cytotoxicity at different effector/target ratios (Figure 3B). Yet, the 4$1 \mathrm{BB} / \mathrm{CD} 3 \zeta \mathrm{CAR}$ showed the least tumor cell lysis which was significantly different from the $\Delta-\mathrm{CD} 28 / \mathrm{CD} 3 \zeta$ CAR. In addition to this, the frequency of IL-2 and IFN- $\gamma$ producing $\mathrm{CD}^{+}$and $\mathrm{CD} 8^{+}$CAR-T cells was elevated upon cognate antigen recognition (Figure $3 C$ and $3 D$ ). Likewise, all the three CAR constructs exhibited antigen-specific IFN- $\gamma$ and IL-2 release (Figure 3E). Even though we observed higher frequency of IL-2 producing cells in the $4-1 B B / C D 3 \zeta$ group (Figure $3 C$ ), the amount of IL-2 secreted by these cells was very limited (Figure 3E). The reduced IL-2 release by the $\Delta-C D 28 / C D 3 \zeta$ compared to $\mathrm{CD} 28 / C D 3 \zeta$ CAR-T cells has already been reported before (11) and is a consequence of the missing Ick signal. However, due to its antigen specificity the elevated IL-2 production by CD28/CD3 $\zeta$ CAR-T cells can only partially explain the observed antigen unspecific proliferation. Besides, $\triangle-C D 28 / C D 3 \zeta$ CAR-T cells revealed maximum antigen-specific IFN- $\gamma$ release (Figure $3 E$ ). Thus, our data demonstrate that $T$ cells redirected with $\Delta-C D 28 / C D 3 \zeta$ show less antigen-independent proliferation with similar antigen-specific proliferation, similar killing to CD28, and enhanced IFN $\gamma$, but reduced IL-2 release. 
Lck lacking CD28 CAR-T cells show improved tumor control in combination with PD-1 blockade in tumor bearing humanized mice.

We aimed to study the survival and efficacy of redirected $T$ cells in a humanized mouse model (huNSG). After comparing human fetal liver (HFL) and leukapheresis products as a source for preparing humanized mice we chose HFL derived $\mathrm{CD}_{34}{ }^{+}$cells to reconstitute NSG mice due to significantly higher levels of human immune cell engraftment in the peripheral blood (Figure S4, B). We found that a very high frequency ( 90\%) of $\mathrm{CD}_{3} 4^{+} \mathrm{HPCs}$ derived from leukapheresis co-expressed CD38 (Figure S4, C), which is a marker for more differentiated progenitor cells, thereby correlating with the poor multi-potency of these cells.

To test survival of redirected T cells in humanized mice, we generated CAR transduced $T$ cells using splenocytes from humanized mice and injected them into recipient mice that were reconstituted from the autologous HPC donor (Figure 4A). After adoptive transfer of redirected T cells and serial blood draws (Figure 4B), CAR-T cells could be detected in the peripheral blood with almost no significant differences between the groups. Up to at least 44 days, redirected $T$ cells persisted in the blood of huNSG without any antigenic stimulus (Figure $4 C$ \& 4D). At day 44, we found these cells predominantly in the blood and in highest frequency of huNSG mice belonging to $4-1 B B / C D 3 \zeta$ group (75\% mice) compared to $\mathrm{CD} 28 / \mathrm{CD} 3 \zeta$ ( $25 \%$ mice) or $\Delta-\mathrm{CD} 28 / \mathrm{CD} 3 \zeta$ (40\% mice) groups. In addition, we found $\mathrm{CD} 28 / \mathrm{CD} 3 \zeta$ redirected $\mathrm{T}$ cells in the liver, spleen and $\mathrm{BM}$ of $50 \%, 25 \%$ and $50 \%$ of huNSG mice, respectively. $\triangle-C D 28 / C D 3 \zeta$ redirected T cells were observed in the BM of $40 \%$ huNSG mice and $4-1 B B / C D 3 \zeta$ CAR-T cells in the liver of $25 \%$ of huNSG mice (Figure 4E).

After confirming the survival of redirected T cells, we investigated their impact on tumor development in huNSG mice. We injected human fibrosarcoma cells expressing FAP (HT1080FAP) in huNSG (Figure 5A). Prior to tumor inoculation, the expression of FAP and PD-L1 was confirmed by flow cytometry (Figure S3, A). 96\% of HT1080FAP tumor cells co-expressed FAP and PD-L1. The HT1080FAP tumor cell line is xenogeneic to the murine host and allogeneic to the reconstituted human immune compartment of the huNSG. To negate the possibility of the reconstituted human immune compartment impacting on the tumor development (allogenicity of the tumor cell line towards the host immune cells), we examined the correlation of reconstitution frequency $\left(\% \mathrm{CD}_{4} 5^{+}\right.$and $\%$ 
$\mathrm{CD}^{+}$cells in blood) in huNSG with tumor development (after tumor inoculation and prior to injecting redirected T cells). We found that tumor-take in huNSG mice was not significantly affected by the level of reconstitution (Figure S4, D). The tumor bearing humanized mice were similarly distributed into different experimental groups based on reconstitution in blood $\left(\% \mathrm{CD}^{+} 5^{+}\right)$and tumor load (Figure. S4, E), prior to adoptive transfer of redirected T cells. As described previously, we injected tumor in the peritoneal cavity. Due to the strong expression of PD-L1 on the tumor cells (Figure S3, A) and a high frequency of redirected T cells expressing PD-1 (Figure $2 \mathrm{C}$ ) the model allows for the testing of PD-1 blockade with T cells expressing different CAR constructs. Before transfer, there was no in vitro effect of PD-1 blockade with regards to proliferation and antigen-specific cell killing by redirected $T$ cells (Figure S3, B \& C). After implantation of the tumor cells, functionally tested (in vitro) redirected T cells (Figure 5B, C \& D) were transferred in the peritoneal cavity (in proximity to tumor) and PD-1 blocking antibody was administered. Surprisingly, only redirected $T$ cells expressing the $\mathrm{F} 19-\Delta-\mathrm{CD} 28 / \mathrm{CD} 3 \zeta \mathrm{CAR}$ induced significantly attenuated tumor growth (Figure $5 \mathrm{~F}$ ) and provided an improved survival of mice (Figure 5G). FAP expression was confirmed on tumors harvested from mice by immunohistochemistry (Figure $5 \mathrm{E}$ ). No redirected T cells could be measured in the peripheral blood (Figure 5H \& Figure S5, A). Persistence of redirected T cells could be identified in the Tumor Infiltrating Lymphocytes (TILS) and peritoneal lavage (Figure $5 \mathrm{H}$ ). Interestingly, persistence was significantly enhanced in T cells redirected by the $4-1 \mathrm{BB} / \mathrm{CD} 3 \zeta$ CAR but without anti-tumor efficacy. Nevertheless, only the number of redirected T cell with $\Delta-C D 28$ co-stimulation showed a significant inverse correlation with tumor development (Figure 51 \& Figure S5, B). Finally, there was no statistically significant difference in frequency of Tregs infiltrating tumors between the different CAR groups (Figure S5, C) suggesting no prominent role of regulatory $T$ cells for the stronger therapeutic effect mediated by the $\Delta-C D 28 / C D 3 \zeta$ CAR with PD-1 blockade.

\section{First-in-man adoptive transfer of Ick lacking CD28 CAR showed persistence of redirected T cells up to 21 days.}

Based on our initial data we designed a first-in-human clinical protocol (9) for the treatment of MPM patients with FAP-specific redirected T cells and to implement FAP-specific redirected $T$ cells as a platform for combination 
therapies as exemplarily tested in the previously described experiments. In this clinical trial, we aimed to use a new application method for the administration of redirected T cells supported by our experience from mouse models. Redirected T cells were injected in proximity to the malignant cells directly into the pleural infusion (Figure 6I). To better characterize the injection site, pleural effusions of different patients with MPM were analyzed as first step. Some MPM pleural effusions showed prominent levels of TGF- $\beta$, IL-10 and VEGF suggesting an immune suppressive microenvironment (Figure S6). However, these pleural effusions did not block in general the antigen-specific release of IFN- $\gamma$ when compared to cell culture supernatant (Figure 6A). The first patient was treated 21 days after collection of autologous PBMCs and GMP re-direction of his T cells by the F19- $\Delta-C D 28 / C D 3 \zeta$ CAR against FAP (Figure 6B). At the day of transfer, the patient's redirected $T$ cells were also tested ex-vivo (Figure 6D). These cells showed antigen-specific release of IFN- $\gamma$, IL-2, IL-10 and TNF- $\alpha$. A biopsy at 6 months post adoptive transfer confirmed FAP expression mainly in the stroma (Figure 6C). Next, the lymphocyte counts, cytokines and the CAR persistence was evaluated in the peripheral blood according to the study protocol. Initially, lymphocyte counts and cytokines levels (IFN- $\gamma$, IL-2, IL-6, IL-10 and TNF- $\alpha$ ) dropped, followed by an increase of IL-10 at later time points (Figure 6E-G). Most interestingly, we observed $\mathrm{F} 19-\Delta-\mathrm{CD} 28 / \mathrm{CD} 3 \zeta \mathrm{CAR}-\mathrm{T}$ cell expansion which peaked in the peripheral blood at day 21 post infusion (Figure $6 \mathrm{H}$ ). The first patient of the clinical trial showed stable disease for about 1 year after adoptive transfer (Figure 6I). At progression he then received PD-1 blockade for 6 months. Thus, the stable disease might have been supported by the CAR-T cell therapy. 


\section{DISCUSSION}

We previously investigated the therapeutic effect of FAP-specific, redirected T cells as an option for treatment of MPM $(9,11)$. Functional T cells expressing anti-FAP CARs at high level could be generated by standard procedures and these redirected $T$ cells showed antigen-specific activity (11). The most recent research in the field of redirected $T$ cells analyzes a multitude of different CAR constructs, of which CARs with CD28 or 4-1BB co-stimulation are most frequently used. This led us to question, which co-stimulation through the CAR should be combined with FAP-specificity for MPM treatment.

We developed a novel humanized mouse model with autologous redirected T cells, thereby avoiding development of GVHD and allogeneic rejection of the transferred, redirected T cells. In this model, the used tumor cell line is allogeneic to the reconstituted immune compartment of humanized mice. However, even a small number of allogeneic tumor cells $\left(0.1 \times 10^{6}\right)$ resulted in a reliable tumor take. This result is even more surprising since it is estimated that the humanized $T$ cell repertoire contains about $5 \%$ alloreactive $T$ cells, which had no effect on tumor take (25). Therefore, the effects of redirected T cells do not seem to be enhanced by allogeneic endogenous T cells and speaks to the low immunogenicity of the tumor cell line.

We observed improved persistence of autologous redirected $T$ cells in humanized mice, considering previously observed survival of up to three weeks in NSG mice (13). As expected, the 4-1BB/CD3 $\zeta$ CAR performed best with regards to persistence until day 44 in the peripheral blood of humanized mice. Multiple reasons could be responsible for this observation. Humanized mice have low levels of human cytokines, which are essential to support transferred $T$ cells. In vitro redirected $\mathrm{T}$ cells are dependent on continuous support from cytokines like IL-2, IL-7 and IL-15. Some animal models tried to overcome this limitation by expressing human cytokines, like IL-7 transgenic NSG mice and, therefore, are potential candidate models to further improve the herein presented model (26). An alternative explanation for the rather short persistence in mice without human immune system reconstitution could be that $T$ cells are not supported without antigen stimulation and/or HLA stimulation (27). Nevertheless, even in the first patient - who served as the ultimate host for his autologous redirected T cells - the CAR-T cells expanded, but persisted no longer than 21 days at detectable levels in the peripheral blood. 
This rather short persistence in humanized mice and man may also be explained by the state of the T cells. Due to the process by which redirected $T$ cells are produced, the main phenotypes of redirected $T$ cells are effector memory or effector phenotype (13). When comparing T cells expressing the $\Delta$ $\mathrm{CD} 28 / \mathrm{CD} 3 \zeta, \mathrm{CD} 28 / \mathrm{CD} 3 \zeta$ and $4-1 \mathrm{BB} / \mathrm{CD} 3 \zeta \mathrm{CAR}$, which had the same phenotype after production, differences could be observed regarding gene expression profiles induced by antigen stimulation. Previously, the comparison of the CARs using CD28 or 4-1BB highlighted the different gene expression profile indicating different metabolic programs (28). The authors have shown that CAR-T cells with 4-1BB co-stimulation developed more readily a central memory phenotype while CD28 co-stimulation yielded effector memory T cells (28). Noteworthy, in our experiments, the $\mathrm{CD} 28 / \mathrm{CD} 3 \zeta$ CAR showed unspecific proliferation. Similar observation of antigen independent signaling through CD28 co-stimulatory CARs was shown before (29) and attributed to certain framework regions in the scFv fragments. Another study showed that CD28 CARs may mediate constitutive expression of IL-2 and proliferation of T cells (30). Our data indicates that Ick deletion results in improved antigen-specific proliferation which might be in part attributed to less constitutive IL-2 secretion and therefore less tonic signaling. In addition, the $\Delta-C D 28 / C D 3 \zeta$ CAR led to a new and distinct supra-physiological gene expression profile in activated $\mathrm{CD} 8^{+} \mathrm{T}$ cells. It induced the expression of gene programs of effector and memory $T$ cells: glycolysis, exhaustion (effector programs) and fatty acid oxidation and anti-apoptosis (memory programs). This, in theory, advantageous combination did not result in prolonged persistence.

Nevertheless, in vivo functionality of the redirected T cells could be tested with some encouraging results. Only the combination of $\Delta-C D 28 / C D 3 \zeta$ CAR redirected T cells with PD-1 blockade resulted in statistically significant tumor control. In contrast, it was shown recently that redirected T cells with CD28 costimulation showed increased in vivo functionality in a mesothelioma model using immune-compromised mice (31). We speculate that the different results are, in part, attributable to interactions of the humanized immune system and the redirected T cells. One potential argument could be clonal competition for cytokines, another, increased immune suppression by parts of humanized immune system in the tumor microenvironment (e.g. regulatory T cells).

Previously it has been shown that regional delivery of CAR-T cells vastly outperforms systemically infused T cells in mouse models (32). Thus, our line of 
experimentation and the early clinical trial were focused on the local injection of redirected $T$ cells in body cavities harboring the tumor cells (intraperitoneal model system in mice and pleural effusion in the clinical trial). Other clinical trials have also followed this approach to overcome the issue of T cell trafficking (33). Our experimental data indicate that redirected T cells injected into a tumor bearing cavity encounter the tumor and cause tumor control.

Overall, we describe here a first humanized mouse model for autologous redirected T cells. We showed that adoptive transfer of FAP-specific redirected T cells with a special CAR lacking Ick signaling through CD28 co-stimulation, in combination with PD-1 blockade induced transient tumor control. Additionally, we took this approach from bench to bedside and demonstrate the first clinical feasibility of this novel therapeutic concept. Concomitant combinations of PD-1 blockade and FAP-specific CAR-T cells should be clinically explored in the future. 


\section{AUTHOR CONTRIBUTIONS}

PG, JR, MP, PSc and SJ conducted experiments. AK analyzed RNA sequencing data. SS, MH, WJ, TW contributed in patient care. NK and MPr helped with in vivo tumor imaging. AS and ME collected clinical samples and performed pathological evaluations. AT performed GMP production of redirected T cells and PSa did autologous transfer. RS contributed to shipping and storage of redirected T cells. UP, RStu, WW and CR contributed to study design. CR designed CAR constructs. UP and CM designed experiments with humanized mice. PG and UP wrote manuscript. 


\section{ACKNOWLEDGEMENTS}

This work was supported by "Forschungskredit" University of Zurich (Grant number 54171101); Swiss Cancer League (grant number KFS-3115-02-2013 and KFS-4231-08-2017), "Hoch spezialisierte Medizin" of the Canton Zurich, Swiss Tumor Immunology Institute and Zurich Cancer League. We thank the first patient and his family for their strong will to support modern therapies in an open and positive manner. We would like to thank Dorothea Greuter, Claudia Bonvin and Claudia Matter for excellent technical assistance. We thank Hinrich Abken and Markus Chmielewski (University of Cologne, Germany) for the pBullet plasmid. We are indebted to Helga Bachmann for the data management. We further thank George Coukos, Silke Gillessen, Alexander Jetter, Georg Stüssi for volunteering for the safety board. We would like to thank Uta Henze from the SCRM for the quality control process. We express gratitude to Mark Robinson for his assistance and support in analysis of RNA sequencing data. The phase I study of testing of FAP-redirected T cells in MPM was partly planned and designed at the 12th joint ECCO-AACR-EORTC-ESMO Workshop 'Methods in Clinical Cancer Research', Waldhaus Flims, Switzerland, $19-25$ June 2010. 


\section{REFERENCES}

1. Sadelain $M$, Brentjens R, Rivière I. The basic principles of chimeric antigen receptor design. Cancer Discov 2013;3:388-98

2. Jackson HJ, Rafiq S, Brentjens RJ. Driving CAR T-cells forward. Nat Rev Clin Oncol 2016;13:370-83

3. Alcantar-Orozco EM, Gornall H, Baldan V, Hawkins RE, Gilham DE. Potential limitations of the NSG humanized mouse as a model system to optimize engineered human T cell therapy for cancer. Hum Gene Ther Methods 2013;24:310-20

4. Gaska JM, Ploss A. Study of viral pathogenesis in humanized mice. Curr Opin Virol 2015;11:14-20

5. Shultz LD, Brehm MA, Garcia-Martinez JV, Greiner DL. Humanized mice for immune system investigation: progress, promise and challenges. Nat Rev Immunol 2012;12:786-98

6. Weder W, Opitz I, Stahel R. Multimodality strategies in malignant pleural mesothelioma. Semin Thorac Cardiovasc Surg 2009;21:172-6

7. Karrison HK, Rose Y-HCT, Straus MA, Sargis R, Seiwert T. Phase II Trial of Pembrolizumab in patients with Malignant Mesothelioma (MM): Interim Analysis Volume Vol. 12 Journal of Thoracic Oncology.

8. Quispel-Janssen J, Zago G, Schouten R, Buikhuisen W, Monkhorst K, Thunissen E, et al. A Phase II Study of Nivolumab in Malignant Pleural Mesothelioma (NivoMes): with Translational Research (TR) Biopies. 2017.

9. Petrausch U, Schuberth PC, Hagedorn C, Soltermann A, Tomaszek S, Stahel R, et al. Redirected $\mathrm{T}$ cells for the treatment of fibroblast activation protein (FAP)-positive malignant pleural mesothelioma (FAPME-1). BMC Cancer 2012;12:615

10. Kofler DM, Chmielewski M, Rappl G, Hombach A, Riet T, Schmidt A, et al. CD28 costimulation Impairs the efficacy of a redirected t-cell antitumor attack in the presence of regulatory t cells which can be overcome by preventing Lck activation. Mol Ther 2011;19:760-7

11. Schuberth PC, Hagedorn C, Jensen SM, Gulati P, van den Broek M, Mischo A, et al. Treatment of malignant pleural mesothelioma by fibroblast activation protein-specific re-directed T cells. J Transl Med 2013;11:187

12. Heller KN, Upshaw J, Seyoum B, Zebroski H, Münz C. Distinct memory CD4+ T-cell subsets mediate immune recognition of Epstein Barr virus nuclear antigen 1 in healthy virus carriers. Blood 2007;109:1138-46

13. Schuberth PC, Jakka G, Jensen SM, Wadle A, Gautschi F, Haley D, et al. Effector memory and central memory NY-ESO-1-specific re-directed T cells for treatment of multiple myeloma. Gene Ther 2012

14. Weijtens ME, Willemsen RA, van Krimpen BA, Bolhuis RL. Chimeric scFv/gamma receptor-mediated T-cell lysis of tumor cells is coregulated by adhesion and accessory molecules. Int J Cancer 1998;77:181-7

15. Hombach A, Hombach AA, Abken H. Adoptive immunotherapy with genetically engineered T cells: modification of the IgG1 Fc 'spacer' domain in the extracellular moiety of chimeric antigen receptors avoids 'off-target' activation and unintended initiation of an innate immune response. Gene Ther 2010;17:1206-13 
16. Ferlazzo G, Thomas D, Lin SL, Goodman K, Morandi B, Muller WA, et al. The abundant NK cells in human secondary lymphoid tissues require activation to express killer cell Ig-like receptors and become cytolytic. J Immunol 2004;172:1455-62

17. Vignali DA. Multiplexed particle-based flow cytometric assays. J Immunol Methods 2000;243:243-55

18. Strowig T, Chijioke O, Carrega P, Arrey F, Meixlsperger S, Rämer PC, et al. Human NK cells of mice with reconstituted human immune system components require preactivation to acquire functional competence. Blood 2010;116:4158-67

19. Strowig T, Gurer C, Ploss A, Liu YF, Arrey F, Sashihara J, et al. Priming of protective T cell responses against virus-induced tumors in mice with human immune system components. J Exp Med 2009;206:1423-34

20. Wei F, Zhong S, Ma Z, Kong H, Medvec A, Ahmed R, et al. Strength of PD-1 signaling differentially affects T-cell effector functions. Proc Natl Acad Sci U S A 2013;110:E24809

21. Brenchley JM, Karandikar NJ, Betts MR, Ambrozak DR, Hill BJ, Crotty LE, et al. Expression of CD57 defines replicative senescence and antigen-induced apoptotic death of CD8+ T cells. Blood 2003;101:2711-20

22. O'Sullivan D, Pearce EL. Targeting $T$ cell metabolism for therapy. Trends Immunol 2015;36:71-80

23. Xu X, Araki K, Li S, Han JH, Ye L, Tan WG, et al. Autophagy is essential for effector CD8(+) T cell survival and memory formation. Nat Immunol 2014;15:1152-61

24. Kovacs JR, Li C, Yang Q, Li G, Garcia IG, Ju S, et al. Autophagy promotes T-cell survival through degradation of proteins of the cell death machinery. Cell Death Differ 2012;19:144-52

25. Suchin EJ, Langmuir PB, Palmer E, Sayegh MH, Wells AD, Turka LA. Quantifying the frequency of alloreactive $T$ cells in vivo: new answers to an old question. J Immunol 2001;166:973-81

26. van Lent AU, Dontje W, Nagasawa M, Siamari R, Bakker AQ, Pouw SM, et al. IL-7 enhances thymic human $T$ cell development in "human immune system" Rag2-/-IL2Rgammac-/- mice without affecting peripheral $T$ cell homeostasis. J Immunol 2009;183:7645-55

27. Billerbeck E, Horwitz JA, Labitt RN, Donovan BM, Vega K, Budell WC, et al. Characterization of human antiviral adaptive immune responses during hepatotropic virus infection in HLA-transgenic human immune system mice. J Immunol 2013;191:1753-64

28. Kawalekar OU, O'Connor RS, Fraietta JA, Guo L, McGettigan SE, Posey AD, et al. Distinct Signaling of Coreceptors Regulates Specific Metabolism Pathways and Impacts Memory Development in CAR T Cells. Immunity 2016;44:380-90

29. Long $A H$, Haso WM, Shern JF, Wanhainen KM, Murgai M, Ingaramo $M$, et al. 4-1BB costimulation ameliorates $T$ cell exhaustion induced by tonic signaling of chimeric antigen receptors. Nat Med 2015;21:581-90

30. Frigault MJ, Lee J, Basil MC, Carpenito C, Motohashi S, Scholler J, et al. Identification of chimeric antigen receptors that mediate constitutive or inducible proliferation of $T$ cells. Cancer Immunol Res 2015;3:356-67

31. Cherkassky L, Morello A, Villena-Vargas J, Feng Y, Dimitrov DS, Jones DR, et al. Human CAR T cells with cell-intrinsic PD-1 checkpoint blockade resist tumor-mediated inhibition. J Clin Invest 2016;126:3130-44 
32. Adusumilli PS, Cherkassky L, Villena-Vargas J, Colovos C, Servais E, Plotkin J, et al. Regional delivery of mesothelin-targeted CAR T cell therapy generates potent and long-lasting CD4-dependent tumor immunity. Sci Transl Med 2014;6:261ra151

33. Brown CE, Alizadeh D, Starr R, Weng L, Wagner JR, Naranjo A, et al. Regression of Glioblastoma after Chimeric Antigen Receptor T-Cell Therapy. N Engl J Med 2016;375:2561-9 


\section{FIGURE LEGENDS}

Figure 1. Phenotypic profiling of $T$ cells activated with $C D 3 / 28$ beads or $C D 3 / 28$ ab and comparison of transduction efficacies.

$\mathrm{CD}^{+} \mathrm{T}$ cells isolated from buffy donors are incubated with anti-CD3 and anti-CD28 coated beads (CD3/28 beads) or anti-CD3 and anti-CD28 antibodies either supplemented in medium (CD3/28 ab) or plate bound (CD3/28 plate bound). A Frequency (\%) of $\mathrm{CD} 25^{+}, \mathrm{CD} 57^{+}, \mathrm{CD} 69^{+}$, Ki $67^{\text {bright }}$ and PD- $1^{+}$T-cells are compared at day $0,3,5,7$ and 10 after removal of CD3/28 stimulus. Pooled data from four leucocyte concentrate donors is shown $(n=2)$. B After removal of CD3/28 stimulus, T cells are CFSE labelled and frequency (\%) of proliferating cells is measured at day $2,4,6$ and $8 . \mathrm{C} \mathrm{CD} 3 / 28$ ab or $\mathrm{CD} 3 / 28$ beads stimulated cells are transduced to express $\mathrm{CD} 28-\mathrm{CD} 3 \zeta$ or $\triangle-\mathrm{CD} 28 / \mathrm{CD} 3 \zeta$ CARs. Left Panel indicates representative FACS plots showing transduction efficacies after $\mathrm{CD} 3 / 28$ beads or $\mathrm{CD} 3 / 28$ ab stimulation. CAR-T cells are detected using anti human IgG antibody to stain for CAR receptor; gated hulgG ${ }^{+} \mathrm{CD}^{+}$(14\% in CD3/28 beads and $15 \%$ in CD3/28 ab stimulated T cells). Transduction efficacies after CD3/28 beads or $\mathrm{CD} 3 / 28$ ab activation are compared (right panel) $(n=4)$. D CD $8^{+}$cells activated with CD3/28 beads or CD3/28 ab are transduced to express F19-CD28/CD3 $\zeta$ CAR. Frequency (\%) of IFN- $\gamma^{+}$and IL- $2^{+}$CAR-T cells (by intra-cellular staining) and total IFN- $\gamma$ and IL-2 production (by ELISA) (E) is compared in response to antigen-specific (+FAP) stimulation or no stimulation (no FAP). Representative data from one experiment with two buffy donors is shown $(n=2)$. Statistics is done using unpaired t-test. Data is presented as mean \pm S.E.M.

Figure 2. Transcriptome profiling of redirected $\mathrm{T}$ cells and validation of phenotypic markers. RNA sequencing was performed using 3 biological replicates. A Differential expression analysis indicating log fold change (Log2FC) in gene expression of FAP-specific CAR ${ }^{+} \mathrm{CD}^{+}$cells over

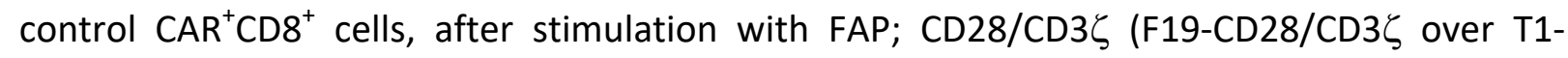
$\mathrm{CD} 28 / \mathrm{CD} 3 \zeta$ ), $\Delta-\mathrm{CD} 28 / \mathrm{CD} 3 z$ (F19- $\Delta-\mathrm{CD} 28 / \mathrm{CD} 3 \zeta$ over $\mathrm{T} 1-\Delta-\mathrm{CD} 28 / \mathrm{CD} 3 \zeta$ ) and 4-1BB/CD3 $\zeta$ (F19$4-1 B B / C D 3 \zeta$ over $T 1-4-1 B B / C D 3 \zeta)$. Heatmaps show differentially regulated genes in (i) Cell cycle pathways (525 genes, enlisted in table S1) (ii) effector or memory phenotype in T cells and (iii) exhaustion and apoptosis. Color key corresponding to each heat map is presented on the upper right corner. Color codes represent Log2FC. B Heatmap showing log fold change (Log2FC) of differentially regulated genes in FAP-specific CARs after antigen stimulation; F19-

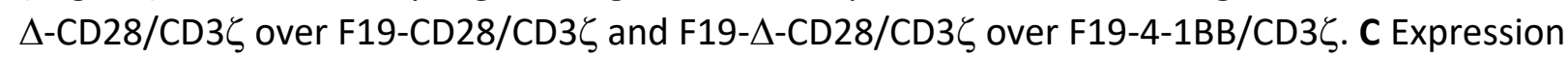
of proliferation marker (Ki67), activation marker (CD25) and immune-checkpoint markers (PD1 and Tim-3) was analyzed by FACS in FAP-specific CAR-T cells (F19-CD28/CD3 $\zeta$, F19- $\Delta$ -

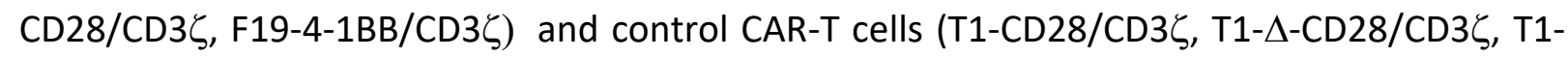
$4-1 B B / C D 3 \zeta$ ) after 6 days of stimulation with antigen (FAP), by comparing the frequencies (\%) of $\mathrm{Ki}^{\mathrm{bright}} \mathrm{CD}^{+} 5^{+}$and PD- $\mathrm{1}^{+}$CAR-T cells and median fluorescence intensity of Tim-3 on CAR-T cells of $\mathrm{CD}^{+}$(i) or $\mathrm{CD}^{+}$(ii) lineage. Representative plots from one experiment with two leucocyte concentrate donors is shown $(n=2)$. Data is presented as mean \pm S.E.M. Statistics is done using unpaired t-test and $p$ values are indicated.

Figure 3. In vitro functional characterization of redirected $\mathrm{T}$ cells with different costimulations.

$\mathrm{CD}^{+}$cells obtained from buffy donors were transduced to express FAP-specific CARs (F19$\mathrm{CD} 28 / \mathrm{CD} 3 \zeta$, F19- $\Delta-\mathrm{CD} 28 / \mathrm{CD} 3 \zeta, \mathrm{F} 19-4-1 \mathrm{BB} / \mathrm{CD} 3 \zeta$ ) or control CARs (T1-CD28/CD3 $\zeta$, T1- $\Delta-$ 
$\mathrm{CD} 28 / \mathrm{CD} 3 \zeta, \mathrm{T} 1-4-1 \mathrm{BB} / \mathrm{CD} 3 \zeta)$ A Proliferation was compared by culturing CAR transduced cells in BrdU supplemented medium and stimulating with $(+)$ or without $(-)$ antigen (FAP). Frequency of proliferating cells was determined by first gating on hulgG ${ }^{+}\left(\mathrm{CAR}^{+}\right)$cells followed by further selecting BrdU ${ }^{+}$cells. Pooled data from 8 buffy donors $(n=4)$ is shown. Statistics is done using one way Anova with Tukey's post test for multiple comparison. B $\mathrm{CD} 3^{+}$CAR-T cells were co-cultured with HT1080FAP tumor cells at specified Effector/Target (E:T) ratios and tumor cell lysis was measured. Intra-cellular staining was performed to measure the frequency (\%) of IL-2 (C) and IFN- $\gamma$ (D) producing CAR-T cells of CD8 (top panel) or CD4 (bottom panel) lineage in response to antigen-specific stimulation (+) or no stimulation (-) with FAP. E Cytokines IL-2 (top panel) and IFN- $\gamma$ (bottom panel) quantified by ELISA in supernatant from co-culture of $\mathrm{CD}^{+} \mathrm{CAR}-\mathrm{T}$ cells with tumor cells. Representative data from one experiment with 2 buffy donors is shown $(n=4)$. $P$ value is calculated using unpaired t-test. Data is presented as mean \pm S.E.M.

Figure 4. Survival of redirected T cells in humanized mice.

A Splenocytes were harvested from donor humanized NSG (huNSG) mice and transduced to express FAP-specific CARs with different co-stimulations (F19-CD28/CD3, F19- $\Delta-C D 28 / C D 3 \zeta$ and $\mathrm{F} 19-4-1 \mathrm{BB} / \mathrm{CD} 3 \zeta)$. Redirected $\mathrm{T}$ cells were then injected into recipient huNSG mice. $\mathrm{B}$ Time line of the adoptive transfer experiment is shown. Redirected $T$ cells were injected intravenously at day 0 . Blood was drawn at day 2, 8, 14, 24 and 44 after adoptive transfer. Mice were sacrificed at day 44 and organs were harvested. C Copies of CAR gene per $\mu \mathrm{g}$ of DNA in blood at day 2, 8, 14, 24 and 44 as quantified by qPCR. Mean CAR copies corresponding to each group and time point are indicated (-) and mentioned (right panel). Each circle represents one qPCR replicate ( 6 replicates per mouse). Dashed line indicates minimum detection threshold. D Number of mice ( $Y$-axis) that showed positive CAR copies in the blood at specified time points (X-axis) in the F19-CD28/CD3 $\zeta$ (top), F19- $\Delta-C D 28 / C D 3 \zeta$ (middle) and F19-4-1BB/CD3 $\zeta$ group (bottom). E Copies of CAR gene per $\mu$ g of DNA in blood, liver, spleen, lungs and BM of harvested mice at day 44. Each circle illustrates one qPCR replicate ( 6 replicates per mouse). Mean values are marked (-). Right panel shows number of mice ( $Y$-axis) that showed positive CAR copies in corresponding organs in each group (X-axis). Representative data from one experiment with 5 mice per group is shown $(n=3)$.

Figure 5. Redirected $\mathrm{T}$ cells with $\Delta$-CD28 co-stimulation show better tumor control in humanized mice and persistence in tumor infiltrating lymphocytes (TILs) and peritoneal lavage (PL).

A Timeline of adoptive transfer. HT1080FAP cells were injected intra-peritoneally in huNSG mice at day 0 , followed by measuring tumor in IVIS at day 1 . After grouping mice based on tumor development, redirected $\mathrm{T}$ cells produced from donor matched littermates were injected at day 2 at E:T = 4:1 to 8:1. Blood was drawn on day 7, 15 and the time of sacrifice. Tumor measurements were performed at day 1, 8, 13 and 18 post tumor injection. Mice were sacrificed based on pre-defined endpoints and the experiment was terminated at day 27. Starting from day 2, mice received PD-1 blocking antibody every fourth day. FAP-specific redirected $T$ cells produced from donor matched littermates of huNSG, were co-cultivated with tumor cells expressing FAP (HT1080FAP) or no FAP (HT1080PA) with or without PD-1 blocking antibody (anti-PD-1) and $\mathbf{B}$ IFN- $\gamma$ and $\mathbf{C}$ IL-2 release in supernatants and $\mathbf{D}$ in vitro tumor cell lysis is shown $(n=2)$. P-value calculated using unpaired t-test. E Representative tumor section of a mouse stained for FAP (right panel) or secondary antibody control (left 
panel), original magnification, 400X. F Tumor volume measured in vivo as photons per second (in IVIS) at day 1, 8, 13 and 18 was plotted and area under the tumor growth curve (AUC) was calculated for each mouse. Top panel shows representative plot from one mouse with AUC highlighted in grey. Bottom panel shows comparison of tumor growth measured as AUC. Each dot represents the AUC of one mouse. Data is presented as mean \pm S.D. P-value is calculated using Mann Whitney test. G Percentage of survival of mice is indicated by a Kaplan Meier curve. $\mathbf{P}$ value is calculated using log rank test. $\mathbf{H}$ Copies of CAR gene per $\mu \mathrm{g}$ of DNA was quantified by qPCR in blood, TILs, PL and spleen of harvested mice (Left panel). Each circle indicates one qPCR replicate (total 3 replicates per mouse). Dashed line indicates minimum detection threshold. Right panel indicates number of mice (Y-axis) from each group (X-axis) that showed positive CAR copies in the corresponding organ. $\mathrm{P}$ value is calculated using Fischer's exact test. I Correlation of copies of $\mathrm{F} 19-\Delta-\mathrm{CD} 28 / \mathrm{CD} 3 \zeta$ gene in TILs with tumor growth (area under the curve). Data is presented as mean \pm SEM. Spearman correlation coefficient $(r)$ and $p$ value $(p)$ is mentioned. Each dot is one mouse $(n=11)$. Error bars depicts the variation between $q P C R$ replicates. Cumulative data from 3 cohorts of mice in two independent experiments is shown (total mice per group $=11$ ).

\section{Figure 6. First-in-man adoptive transfer of Ick lacking CD28 CAR showed persistence of redirected $\mathrm{T}$ cells up to $\mathbf{2 1}$ days in peripheral blood.}

A F19- $\Delta-C D 28 / C D 3 \zeta$ redirected T cells were incubated with HT1080FAP target cell in pleural effusions from different donors (1-9) or culture media (R10) and IFN- $\gamma$ release was measured by ELISA. B Time schedule of the clinical phase-I trial C Biopsy of patient, 6 months after adoptive transfer, stained for FAP (original magnification, 400X). D GMP produced, redirected FAP-specific T cells were tested in vitro before transfer in different effector to target ratios and cytokines were measured. "CAR-" indicates untransduced T cells. E Absolute counts of leukocyte subsets F Percentages of leukocyte subsets $\mathbf{G}$ Cytokine levels measured in the peripheral blood and $\mathbf{H}$ copy numbers of the CAR $(F 19-\Delta-C D 28 / C D 3 \zeta)$ gene in the peripheral blood measured in relation to peripheral blood mononuclear cell (PBMC) DNA amount (per $\mu \mathrm{g}$ ). I CT scan of lungs on different time points with respect to adoptive transfer. $\rightarrow$ indicates the pleural effusion, in which the redirected T cells were injected. 
A
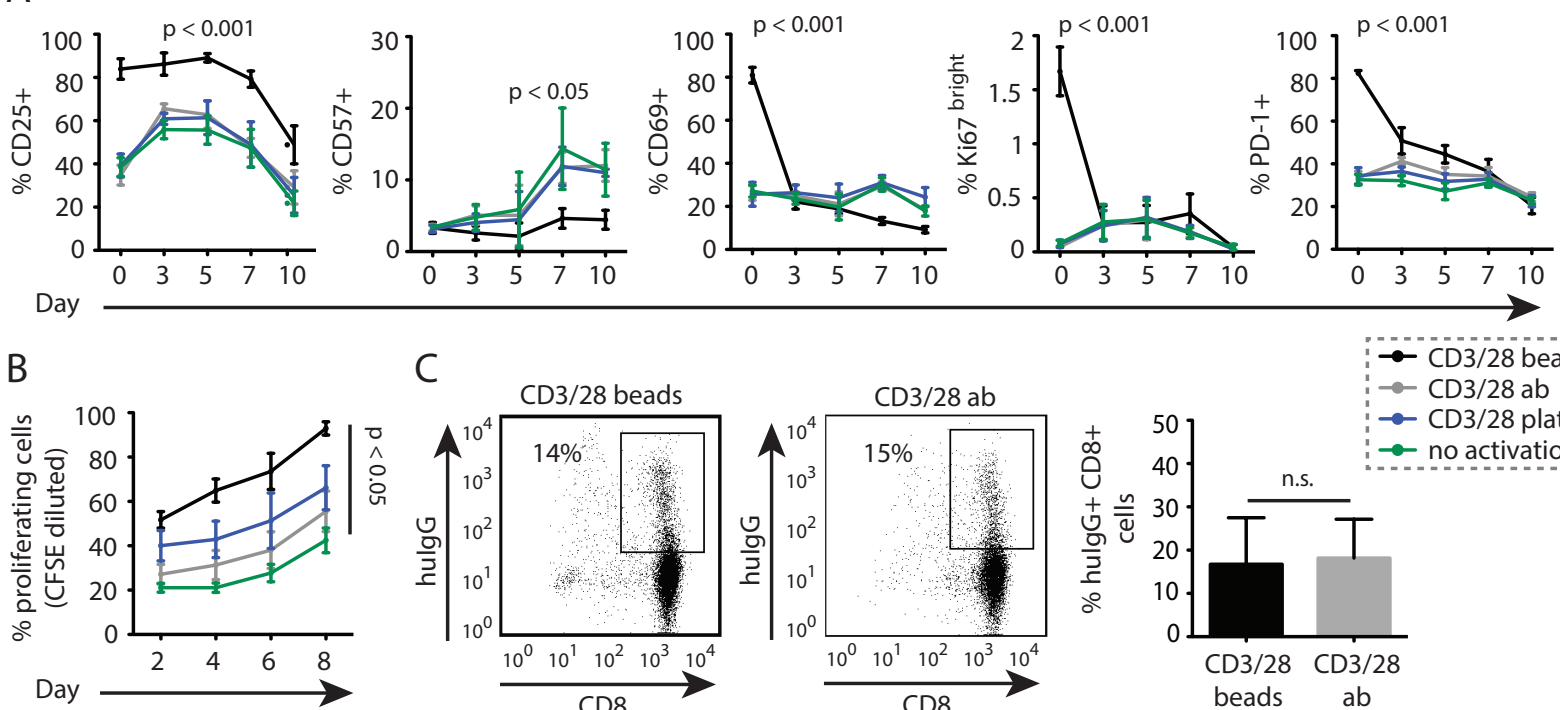

C

D
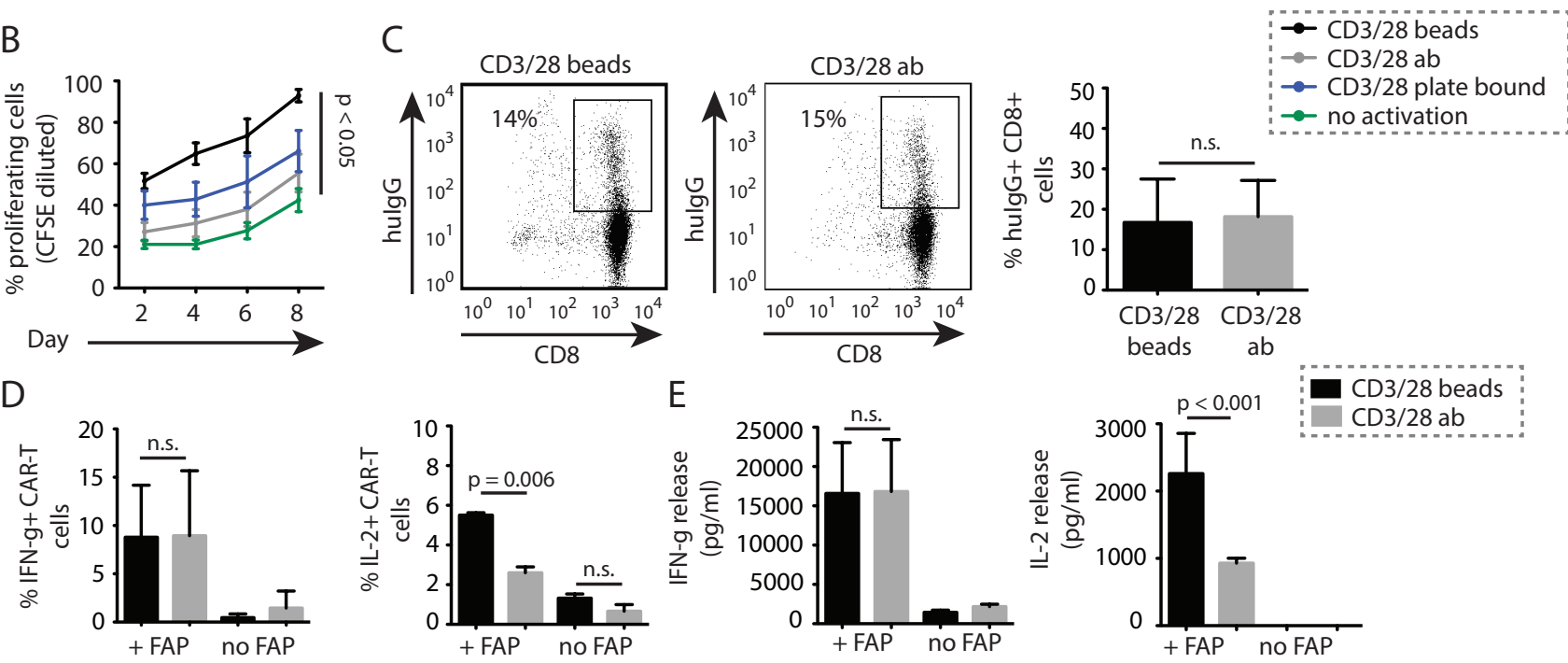

Figure 1 
A

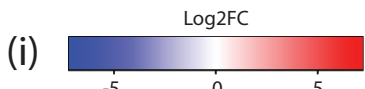

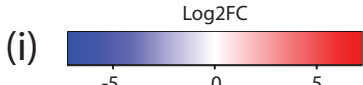

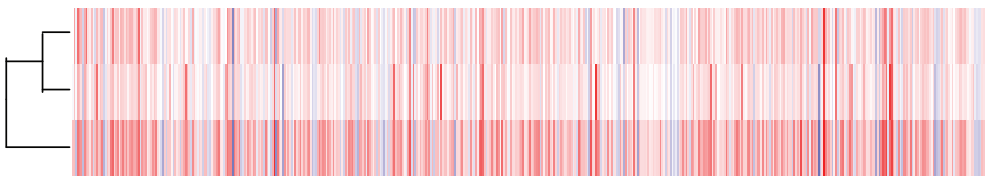

Cell cycle (525 genes)

4-1BB/CD3z

$\mathrm{CD} 28 / \mathrm{CD} 3 z$

$\mathrm{D}-\mathrm{CD} 28 / \mathrm{CD} 3 z$

(ii)

Log2FC

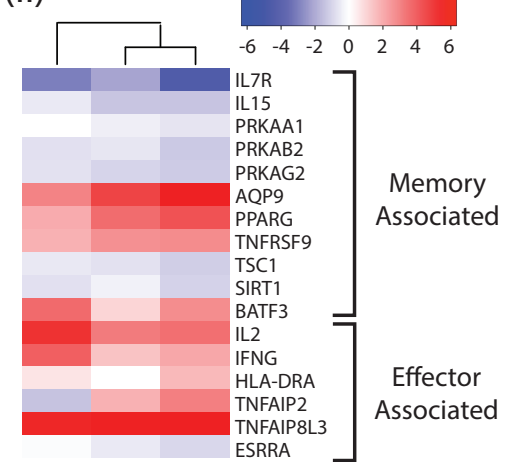

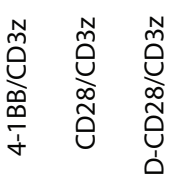

C

(i) Of CD8+ CAR-T cells
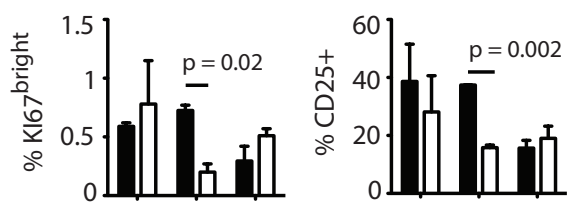

(iii)

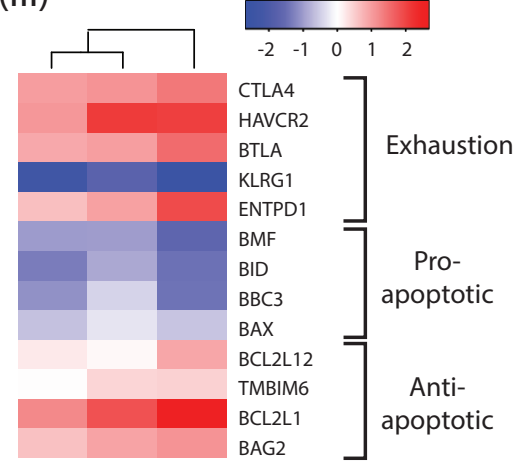

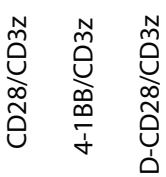

FAP specific CAR (F19) + FAP Control CAR (T1) + FAP
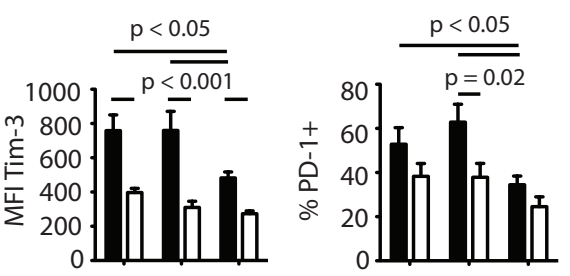

(ii) Of CD4+ CAR-T cells
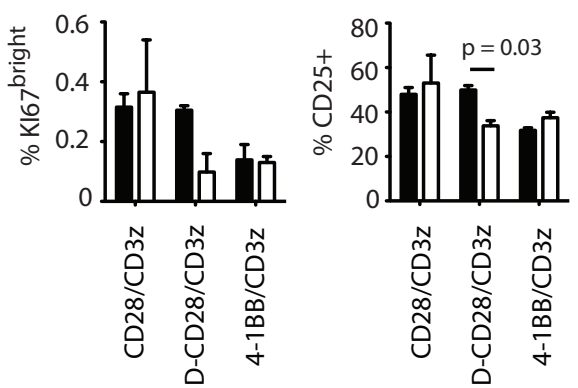

Figure 2
B

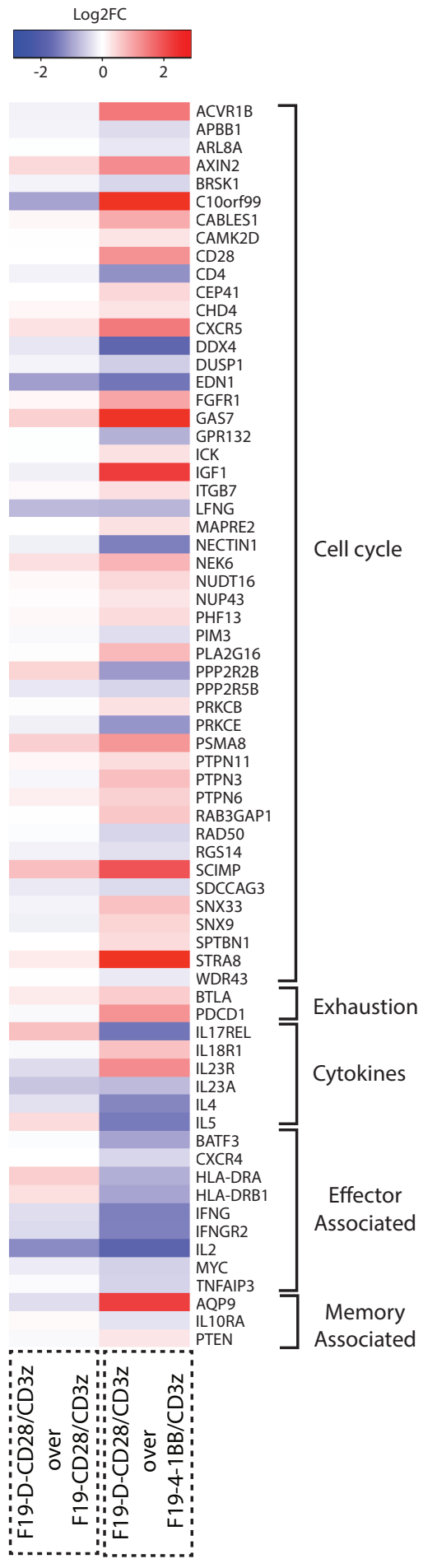


A

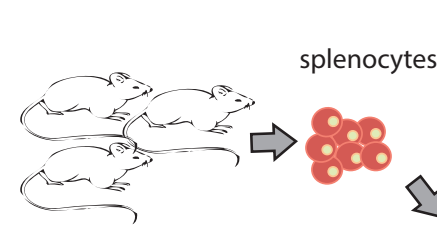

Donor huNSG

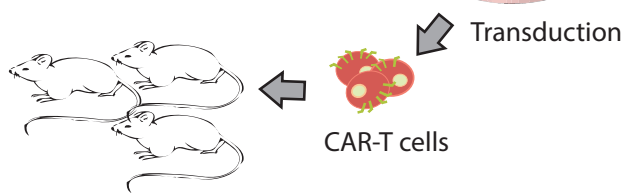

Recipient huNSG

C

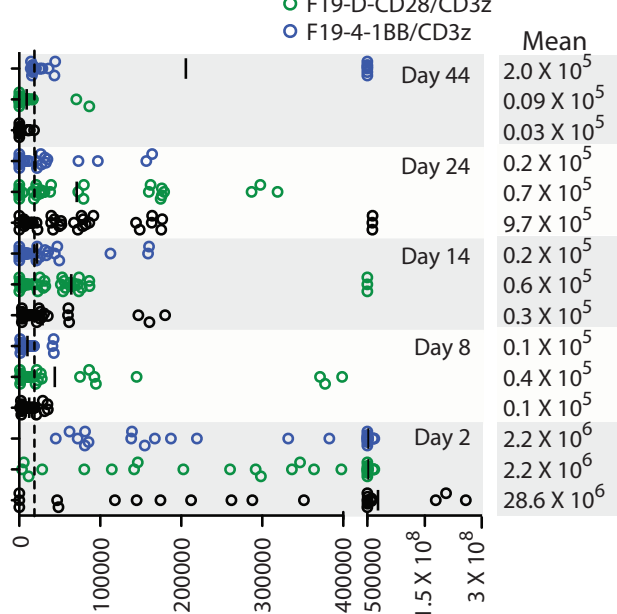

Copies of CAR gene per mg of DNA in blood
B

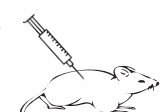
containing

CAR plasmid

$凹$

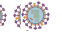

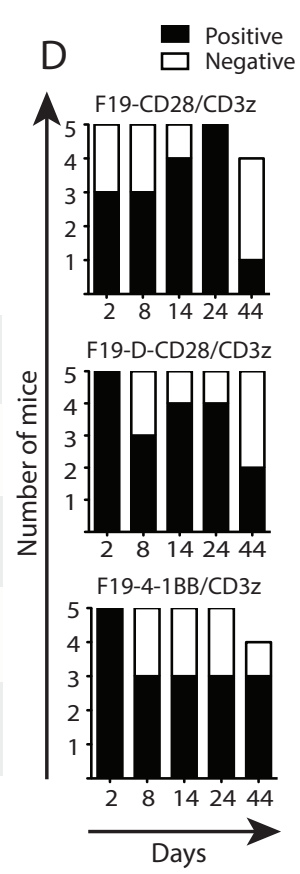

Days
huNSG

Blood drawn

$\uparrow$ Intra-venous adoptive transfer CAR-T cells

Sacrifice

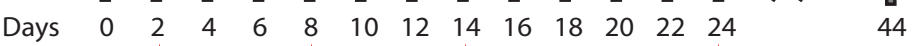

$\uparrow$

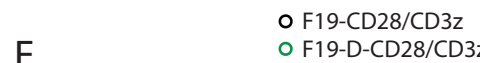

F19-D-CD28/CD3z o F19-4-1BB/CD3z Negative

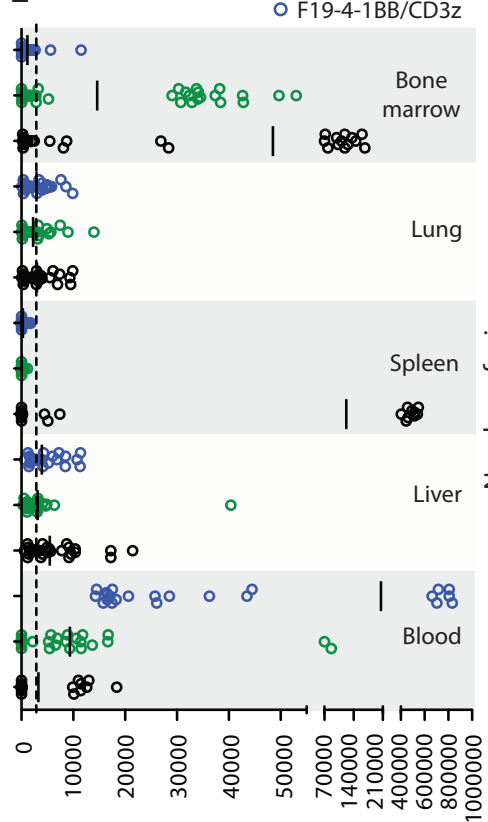

Copies of CAR gene per mg of DNA

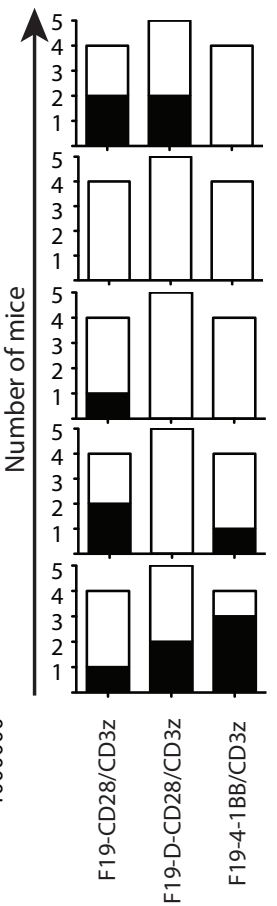

Figure 4 


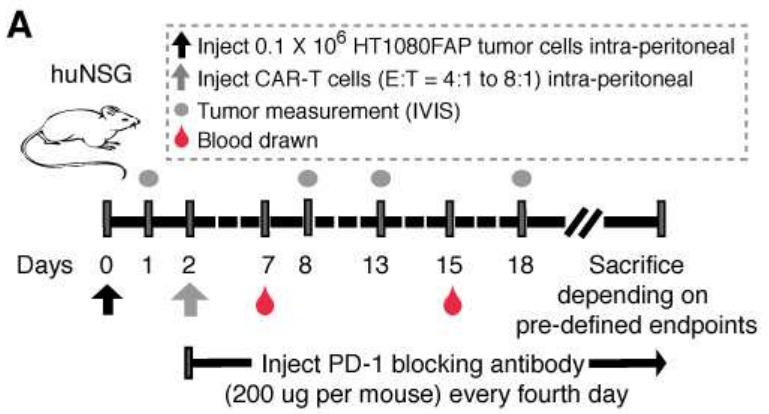

D

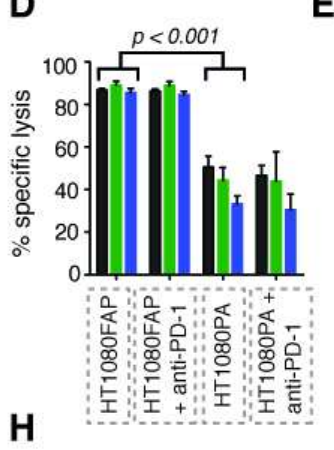

E

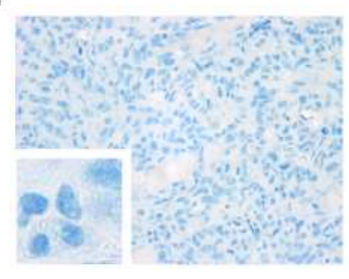

secondary antibody

H

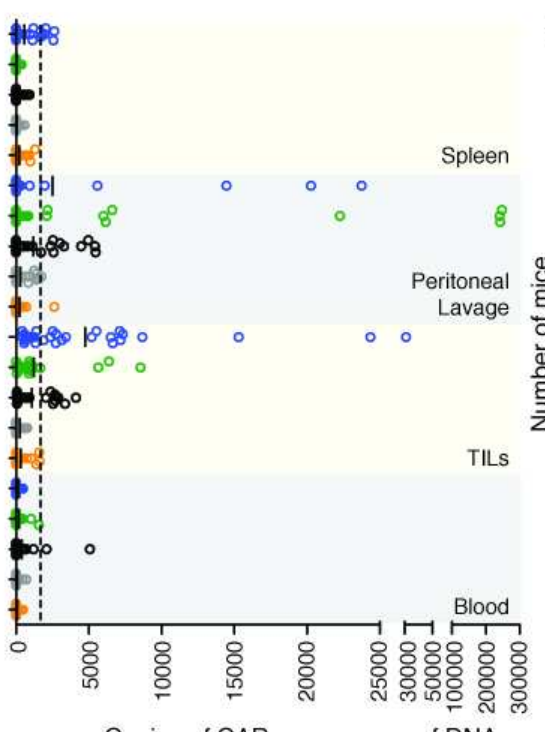

Copies of CAR gene per $\mu \mathrm{g}$ of DNA
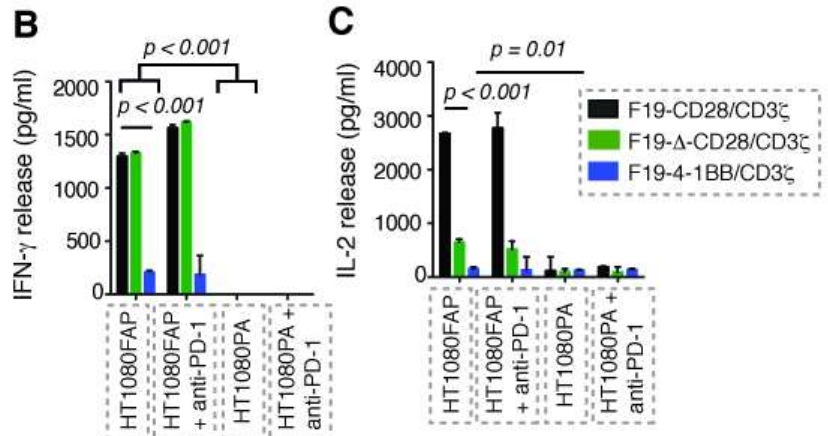

G

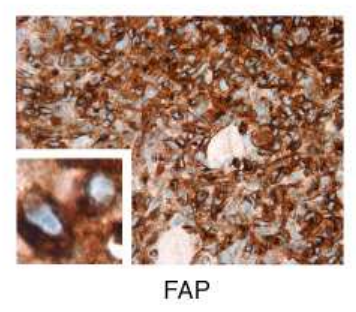

$\mathbf{F}$

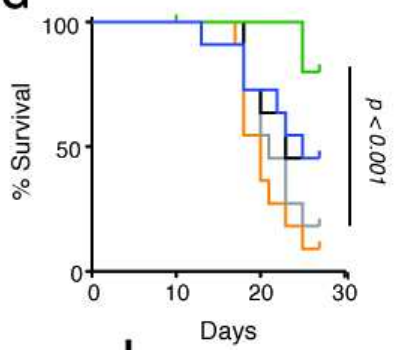

I
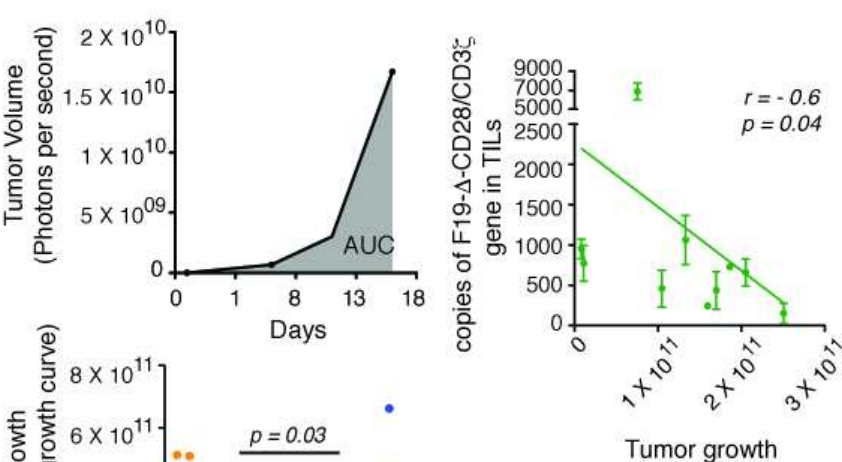

(Area under growth curve)

Figure 5 
A

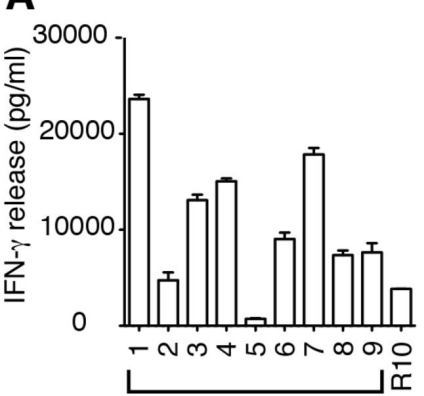

D
B

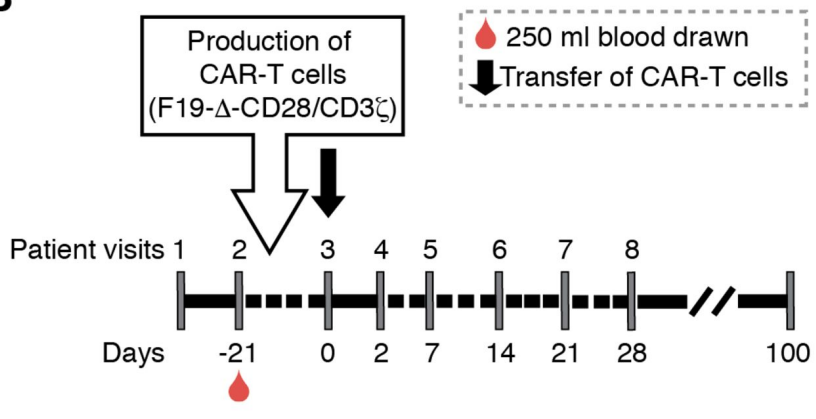

C

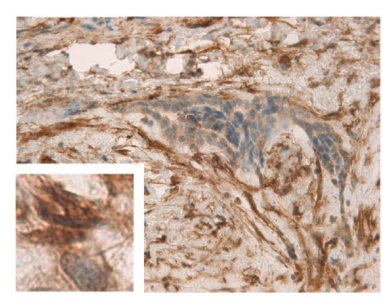

$\square$ HT1080

- HT1080 FAP+ CD3/28

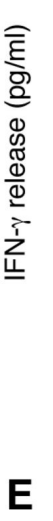

E

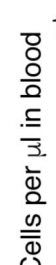
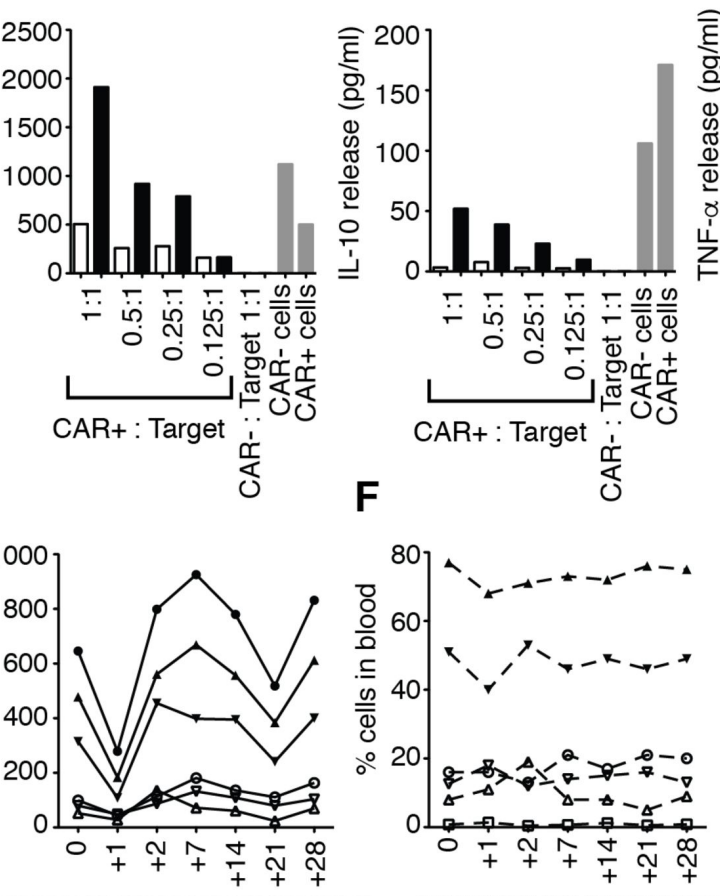

- Lymphocytes $0-\mathrm{CD} 8+$ $\rightarrow \mathrm{CD3}+\quad \triangle \mathrm{CD} 19+$ $\rightarrow \mathrm{CD} 4+$ $\checkmark \mathrm{CD} 56+$

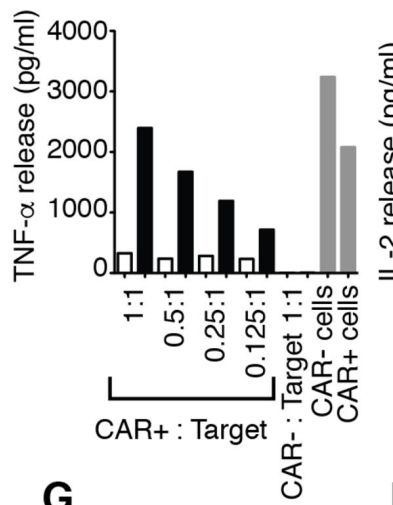

$G$

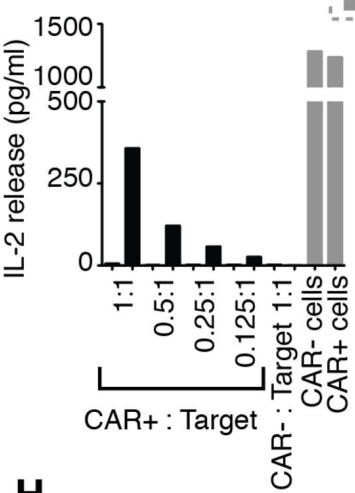

H
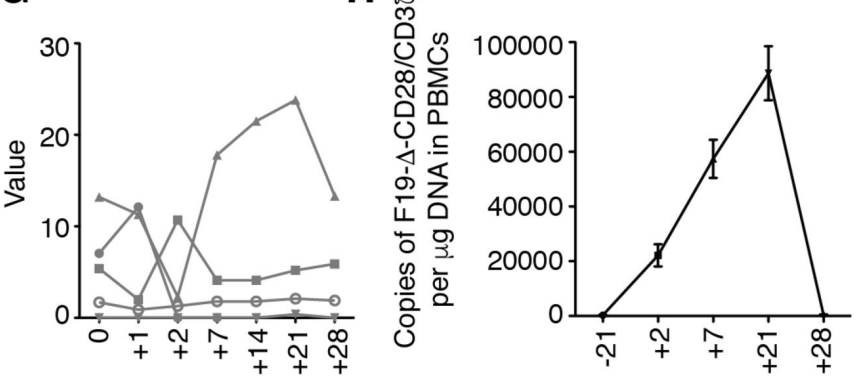

Days with respect to adoptive transfer

\section{1}

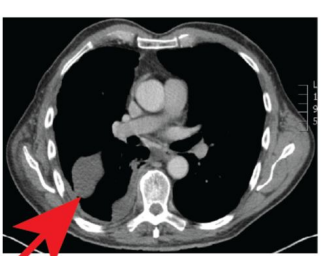

Day 0

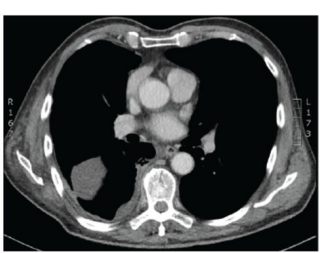

Day +35

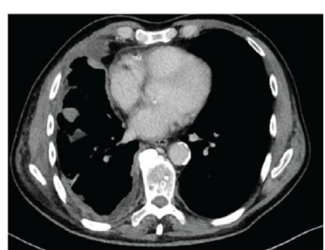

Day +332 Research. 


\section{Clinical Cancer Research}

\section{Aberrant Lck signal via CD28 co-stimulation augments antigen-specific functionality and tumor control by redirected T cells with PD-1 blockade in humanized mice}

Pratiksha Gulati, Julia Rühl, Abhilash Kannan, et al.

Clin Cancer Res Published OnlineFirst May 10, 2018.

\section{Updated version Access the most recent version of this article at: doi:10.1158/1078-0432.CCR-17-1788}

Supplementary Access the most recent supplemental material at:

Material http://clincancerres.aacrjournals.org/content/suppl/2018/05/10/1078-0432.CCR-17-1788.DC1

Author Author manuscripts have been peer reviewed and accepted for publication but have not yet Manuscript been edited.

E-mail alerts Sign up to receive free email-alerts related to this article or journal.

Reprints and To order reprints of this article or to subscribe to the journal, contact the AACR Publications

Subscriptions Department at pubs@aacr.org.

Permissions To request permission to re-use all or part of this article, use this link http://clincancerres.aacrjournals.org/content/early/2018/05/10/1078-0432.CCR-17-1788.

Click on "Request Permissions" which will take you to the Copyright Clearance Center's (CCC) Rightslink site. 